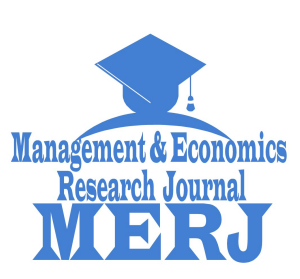

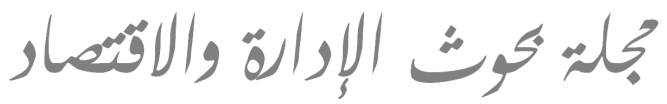

Management \& Economics Research Journal ISSN 2710-8856 (Online)

ISSN 2676-184X (Print)

مجلة بحوث الإدارة والاقتصاد، مجلد 1 عدد 4 (2019)، (2019)، ص 141-159 (15)

Management \& Economics Research Journal, Vol. 1 No. 4 (2019), pp. 141-159

do) https://doi.org/10.48100/merj.v1i4.66

(D) Check for updates

\title{
دور مجلس الإدارة في تطبيق مبادئ حوكمة الشركات العائلية: شركة رويبة "NCA"
}

فطيمة سايح 1

1 أستاذة محاضرة، المركز الجامعي لغليزان (الجزائر)

$\bowtie$ fatima.sayah@cu-relizane.dz

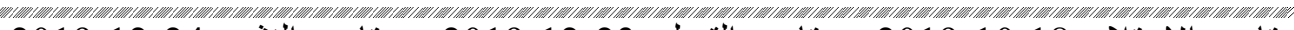

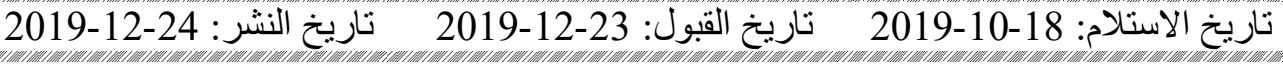

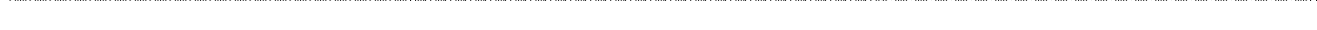

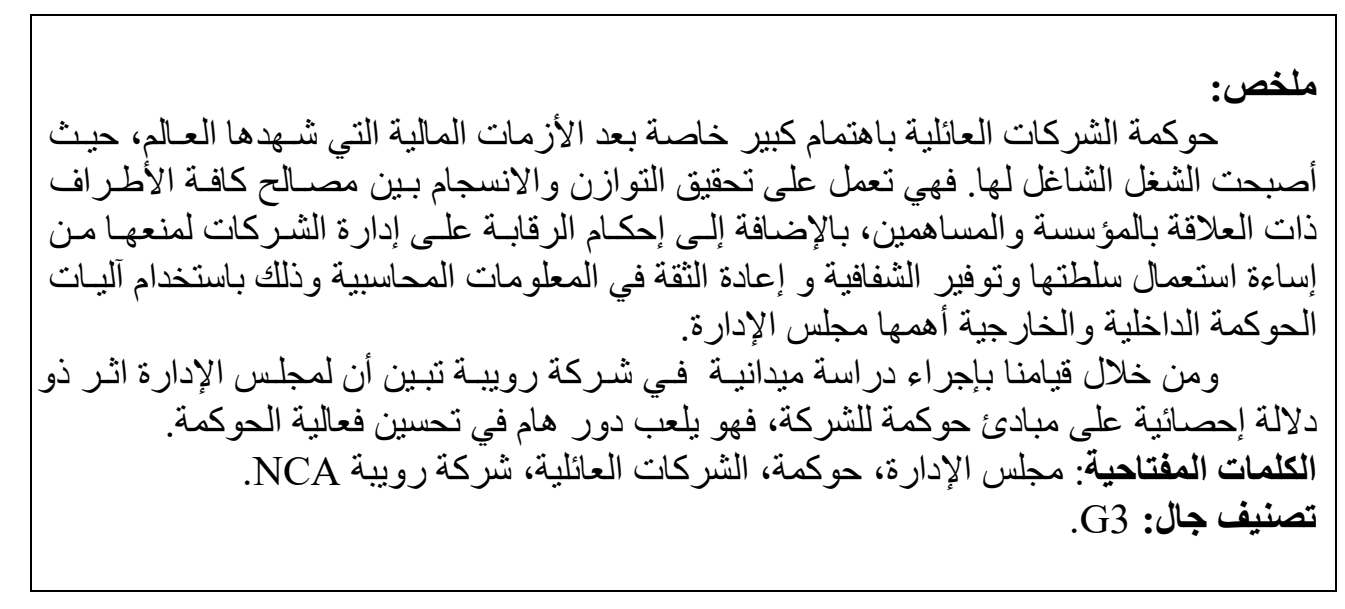




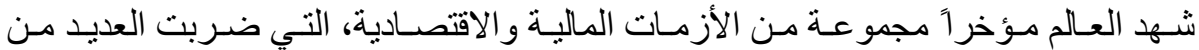

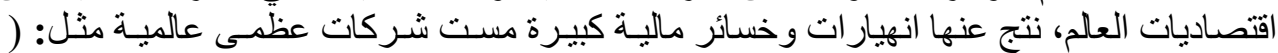
Enron, Worldcom, Parmalat

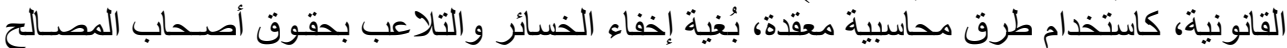

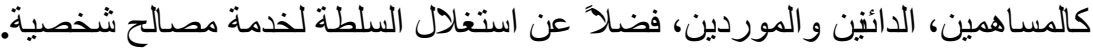

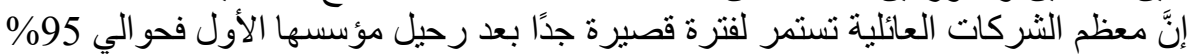

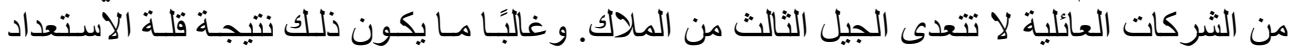

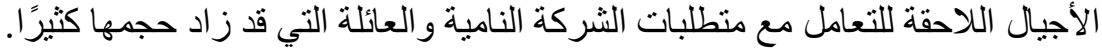

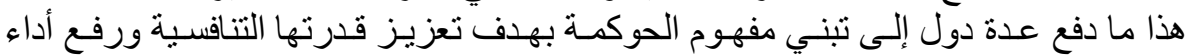

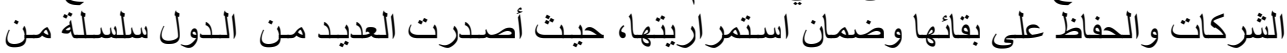

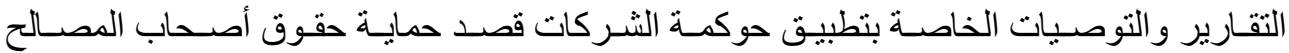

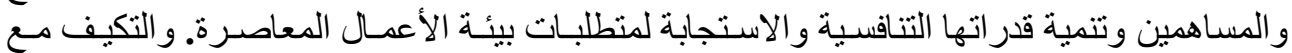

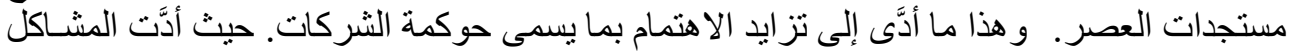

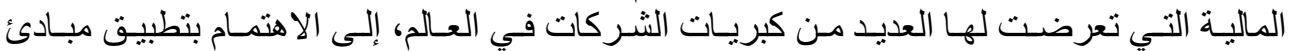

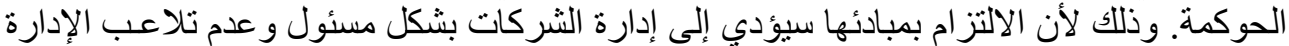

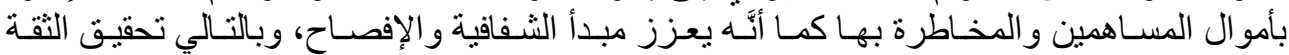

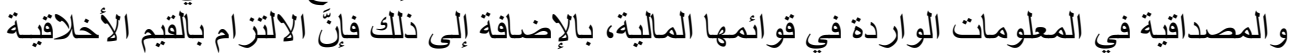

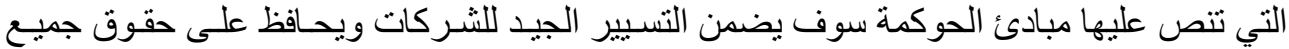

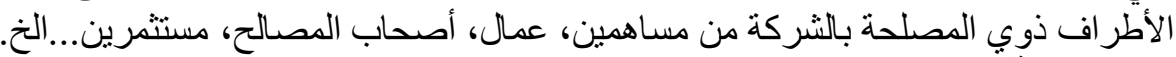
1.1

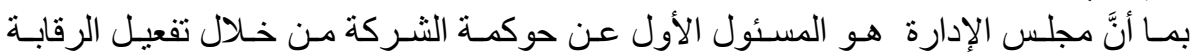

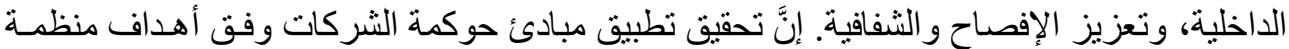

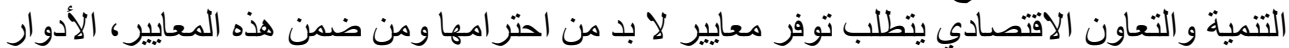

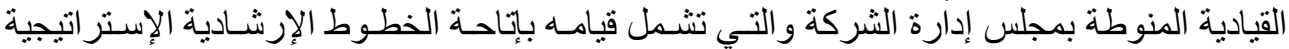

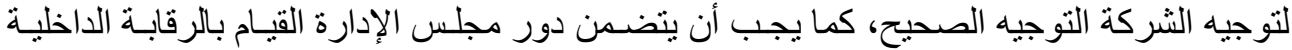

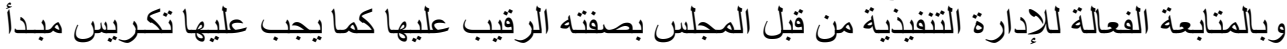
الثفاقية و الإفصاح.

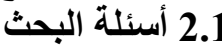

وبالتالي تتمحور إثكالية هذا البحث في السؤال التالي:

ما مدى تأثثير مجلس الإدارة الثركة على تطبيق مبادئ حوكمة الثـركات العائليـة في شـركة رويبـة

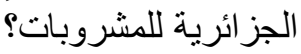

3.1

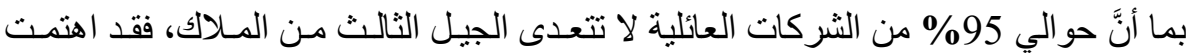

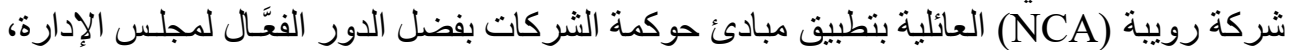

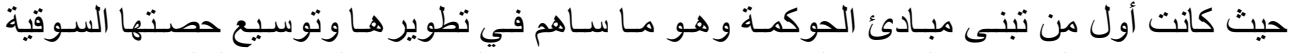

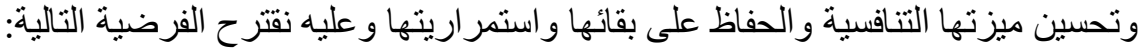

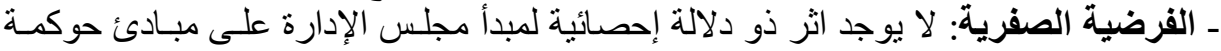

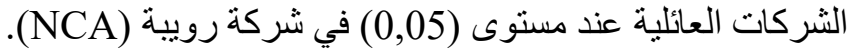




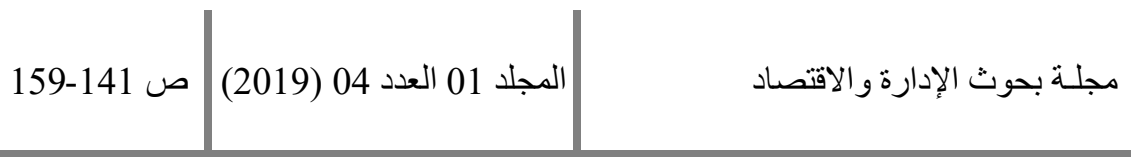

ـ الفرضـية البديلـة: يوجد اثـر ذو دلالـة إحصـائية لمبـدأ مجلس الإدارة على مبـادئ حوكمـة

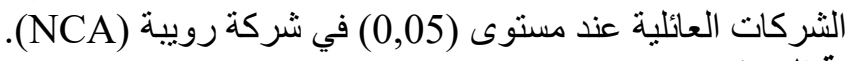

4.1

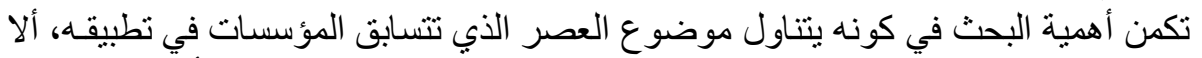

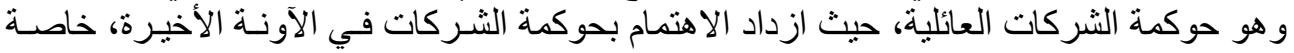

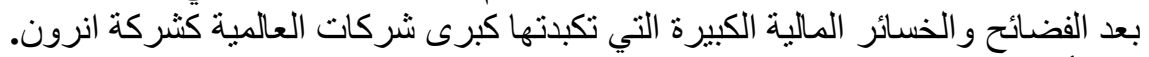

5.1

نُجمل أهداف البحث في النقاط النقاط التالية:

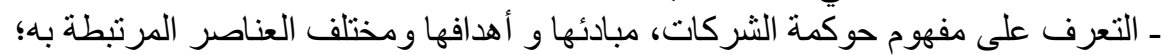
ـ تسليط الضوء على دور مجلس الإدارة في تطبيق مبادئ حوكمة الشركات الثرات العائلية؛

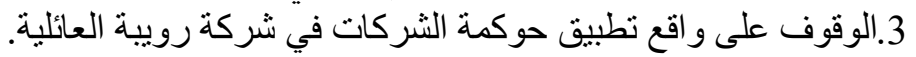

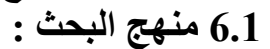

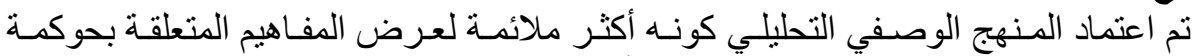

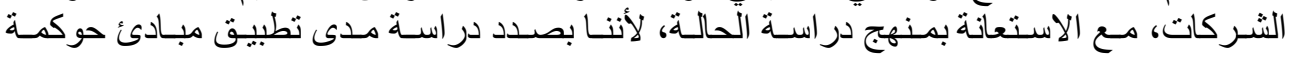

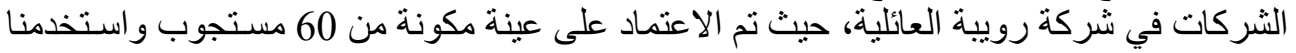

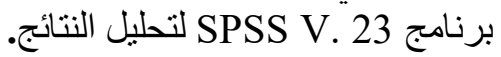
سوف تتم معالجة هذا البحث من خلافل المحاور الثلاث التالية: : 7.1 محاور البحث ـ مفاهيم حول الثركات العائلية ـ الإطار النظري لحوكمة الشركات العائلية

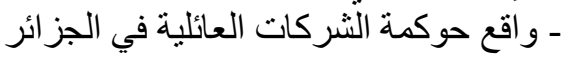

\section{2. - 2فاهيم حول الثركات العائلية}

\section{2 تعاريف حول الشركات العائلية}

يوجد العديد من تعاريف شركات العائلية فهي على سبيل المثنال تللك "الثركات التهات التي تملكها وتُدير ها عائلة واحدة، وتسيطر هذه العائلة على أغلبية التصويت في في الثركة، وئل ويمكن أن تكون العائلة

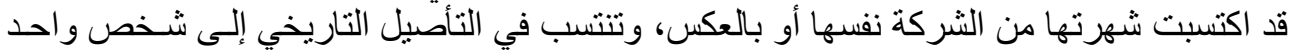

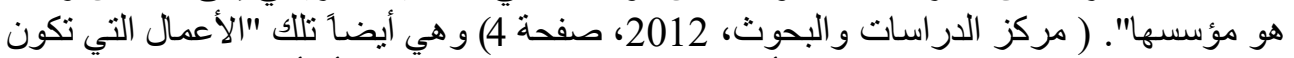

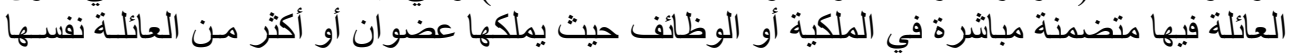

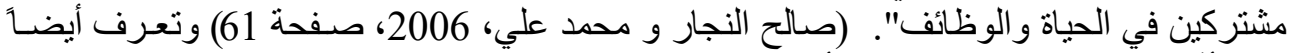

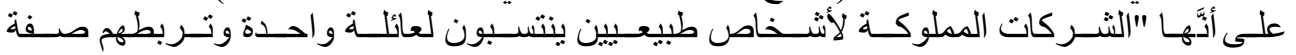

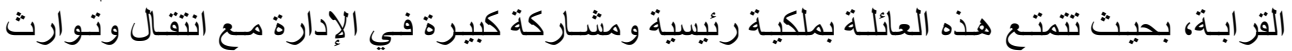

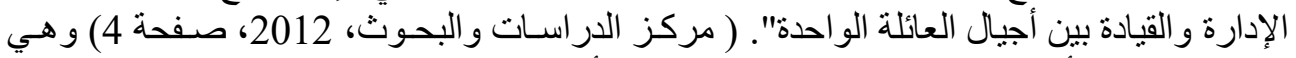

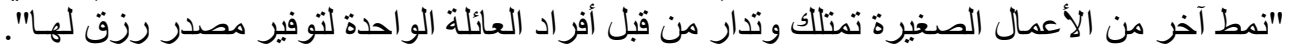

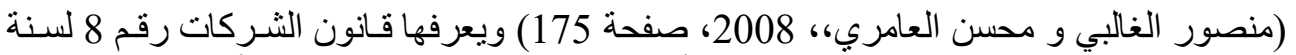

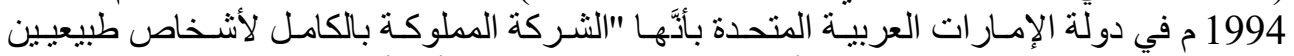

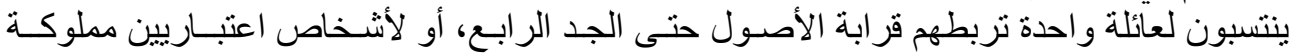

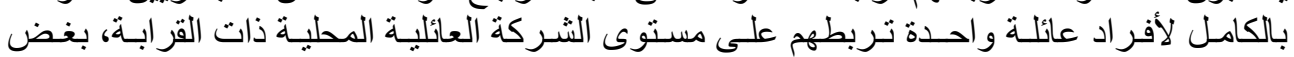

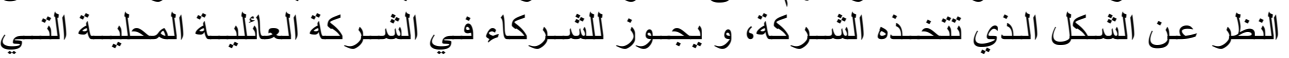




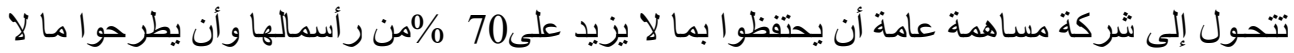

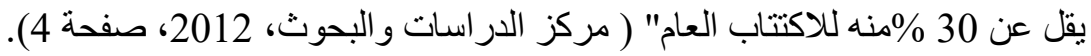

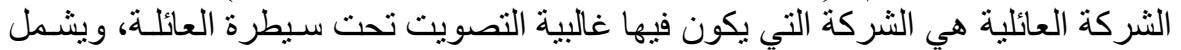

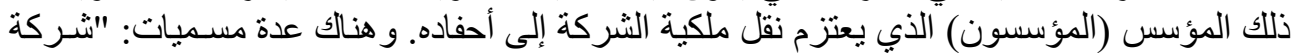

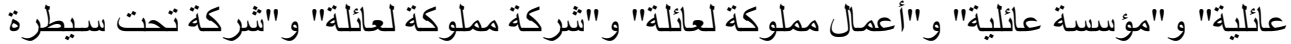

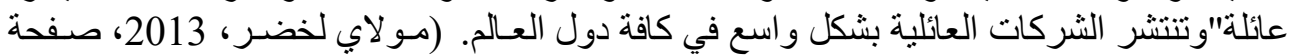

2.2. - 2.2 ميزات الثركات العائلية

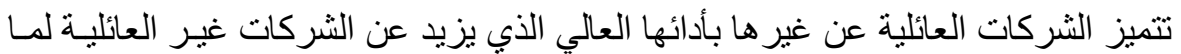

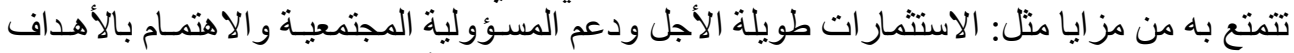

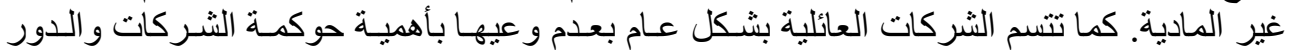

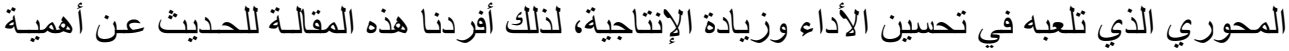

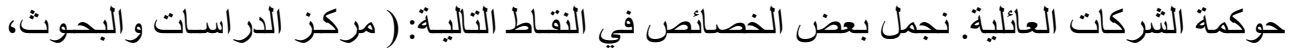

2012، صفحة 5 و6) الماتلة

- ارتفاع درجة الحماس لإنجاح النشاط بين أفراد العائلة و بث روح التحف التحفيز بينهم.

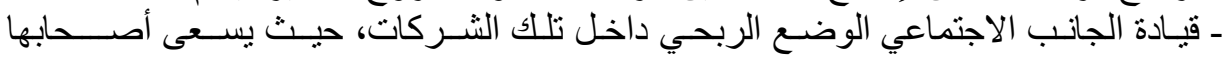

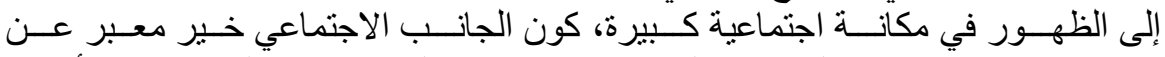

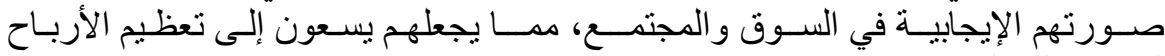
لتحقيق ذلك الهدف. ـ سهولة العمل وسر عة اتخاذ القرار نتيجة لعدم تعقد الهيكل الإداري، والتحرر مـن إجراءات

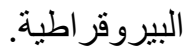

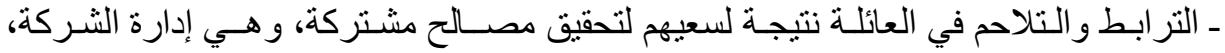

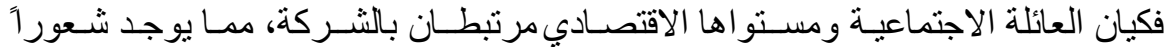

بالانتماء للعائلة الكبيرة. ـ و جود الحافز لمواجهة التحدي الكبير من أجل البقاء واستمر ار العائلة.

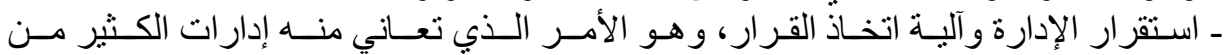

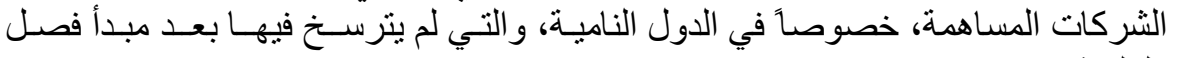

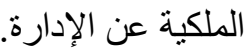

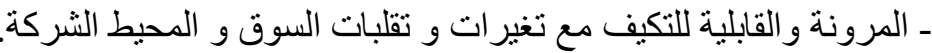

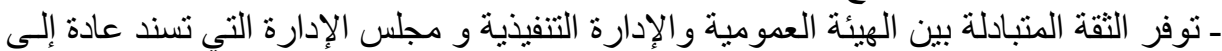

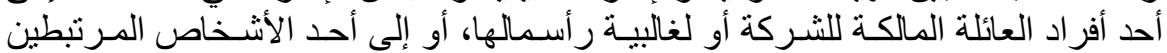

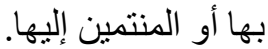

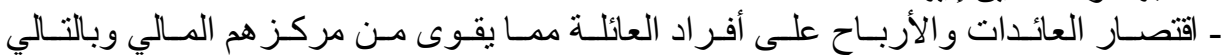

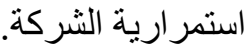

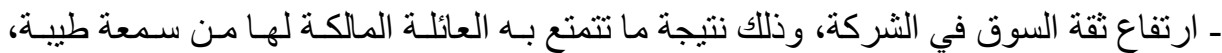

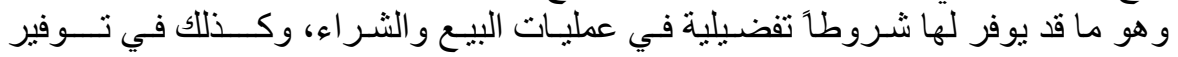

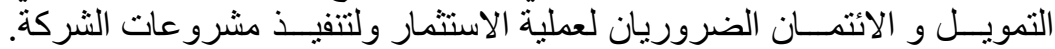

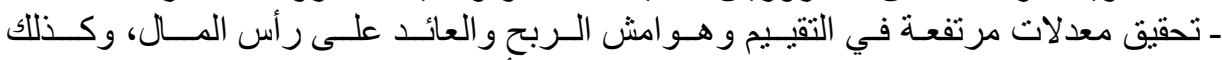

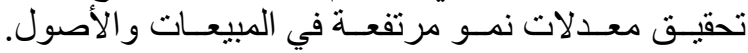


المجلد 01 العدد 04 (2019) | ص 141-159

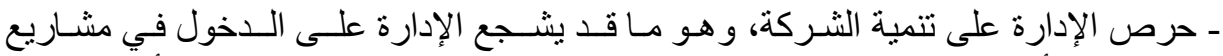

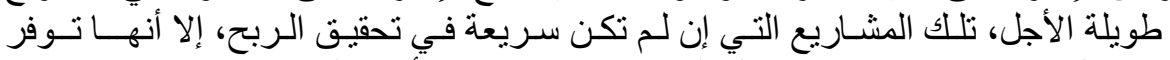

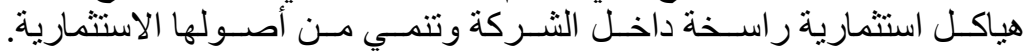
3.2 أهمية الثركات العائلية:

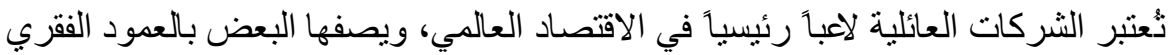

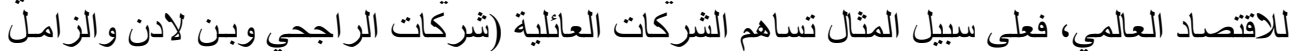

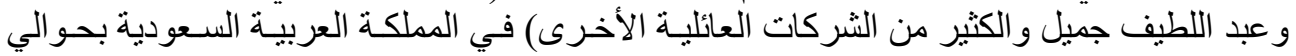
10\% من إجمالي الدخل الوطني.

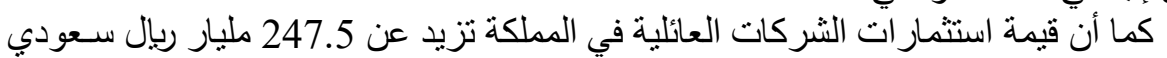

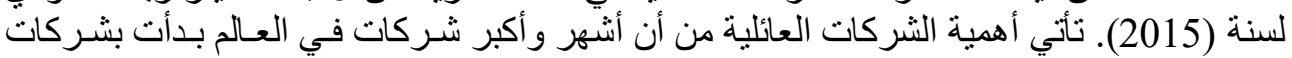

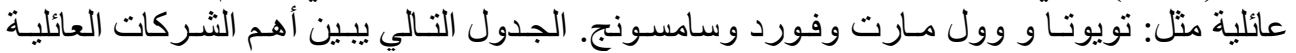

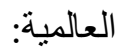

\begin{tabular}{|c|c|}
\hline مجموعة الثركات العائلية & الدول \\
\hline شركة الراجحي، شركة بن لادن، شركة الزامل، ركة جرير & المملكة العربية السعودية \\
\hline شركة الثايع، شركة الخر افي، شركة الغانم & 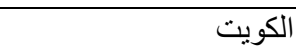 \\
\hline شركة الغرير، شركة الفطيج & المالمارات العربية المتحدة \\
\hline Ford Motors Company, Wal Mart Stores & الو ل الايات المتحدة الأمريكية \\
\hline BMW, Siemens, Mercedes & ألمانيا \\
\hline Kikkoman, ITO-Yokado & اليابان \\
\hline Samsung, LG Group, Hyundai Motors & كوريا الجنوبية \\
\hline Salvatore Ferragamo, Fiat Group, Benetton & ايطاليا \\
\hline LVMH, L'Oréal, Michelin, Carrefour Group & 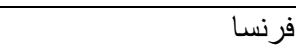 \\
\hline
\end{tabular}

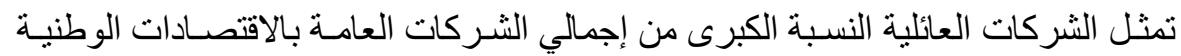

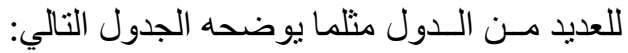

جدول رقم (2): نسب الثركات العائلية من إجمالي الثركات المنواجدة في الدول

\begin{tabular}{|c|c|c|}
\hline \multicolumn{2}{|c|}{ \% الشركات العالثلية من اجمالي الشركات المسجلة } & الدولة \\
\hline النشاطكات ما بقارب من و88\% من & $\% 95-90$ & دول الخليج العربية \\
\hline & $\% 95-70$ & الدول العربية \\
\hline & $\% 90$ & السويذ \\
\hline & $\% 70$ & البرتغال \\
\hline & $\% 95$ & اليطاليا \\
\hline & $\% 80$ & اسبانيا \\
\hline & $\% 88$ & سوبيسرا \\
\hline & $\% 75$ & بريطانيا \\
\hline & $\% 91$ & 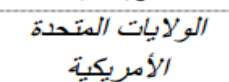 \\
\hline
\end{tabular}

المصدر: (نجــار، 2017، ص111) 
حيث 85 \% مـن الثـركات العالميـة هي شـركات عائليـة و تمثنل 75 \% مـ من الثـركات

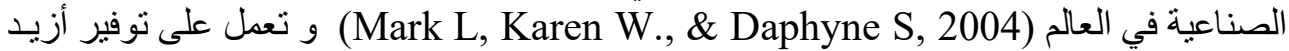
من 60 \% من مناصب العمل و حو الي 35 \% منها ضـمن ترتيب اكبر (500) شـركة في العـالم

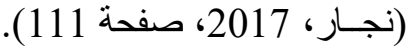

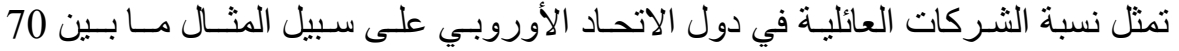

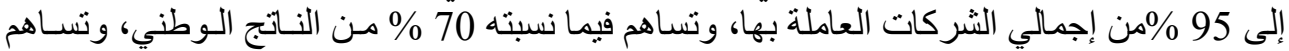

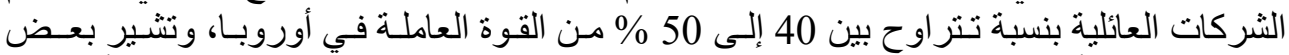

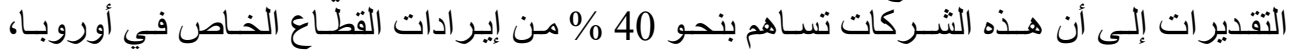

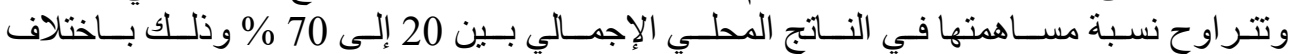

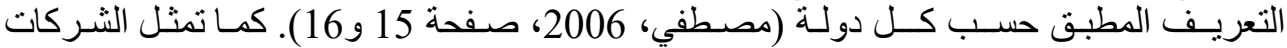

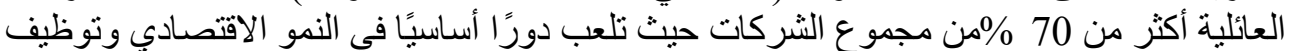

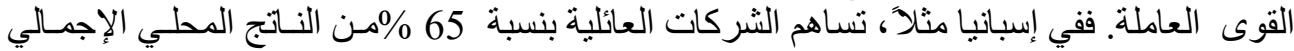

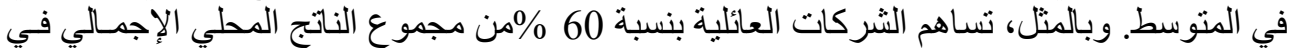
أمريكا اللاتينية. (مو لاي لخضر، فئر، 2013، صفحة 184).

\section{3. الإطار النظري لحوكمة الثركات العائلية}

\section{3}

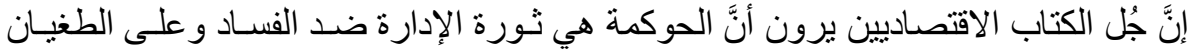

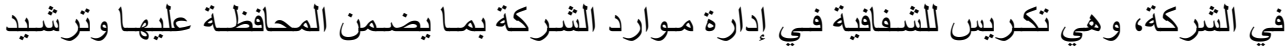

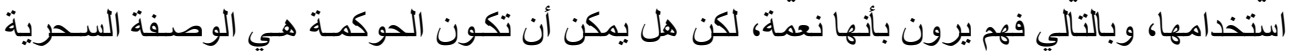

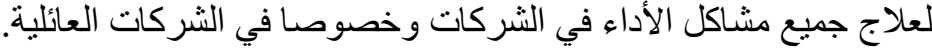

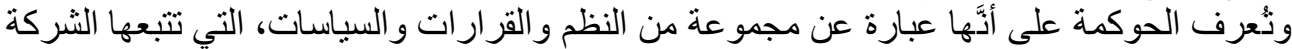

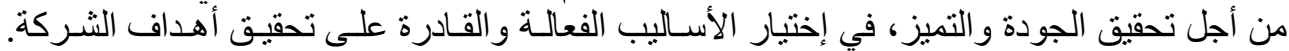

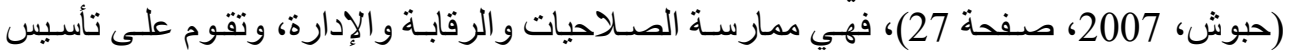

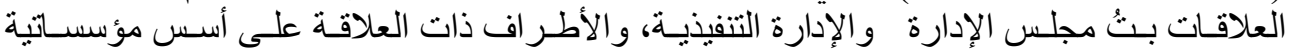

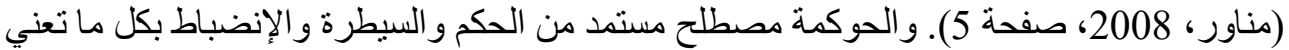

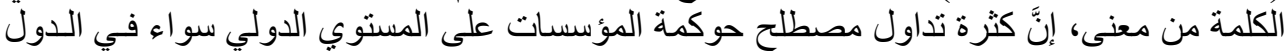

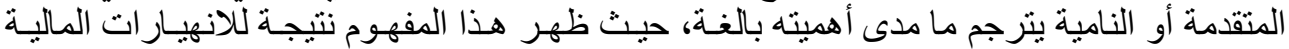

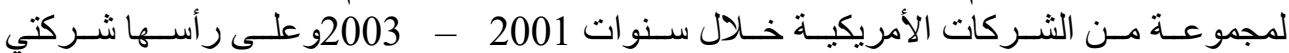
Enron ونorldcom

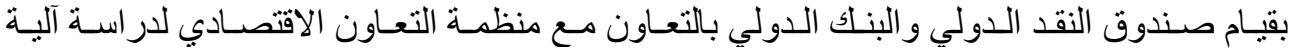

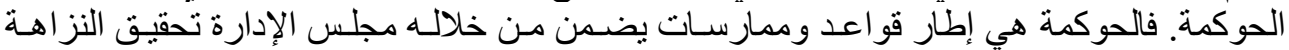

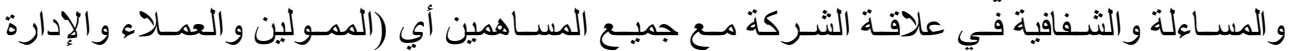

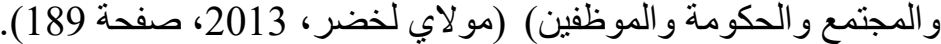
2.3

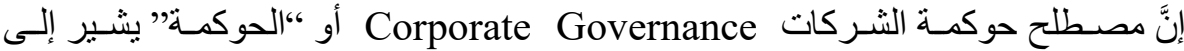

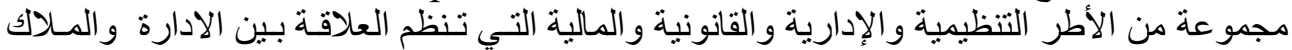

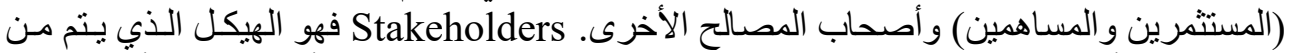

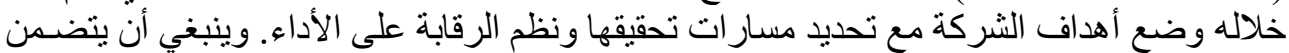




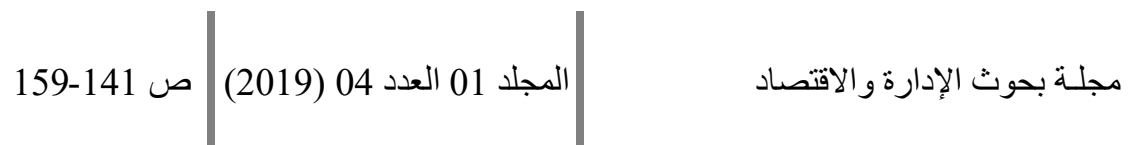

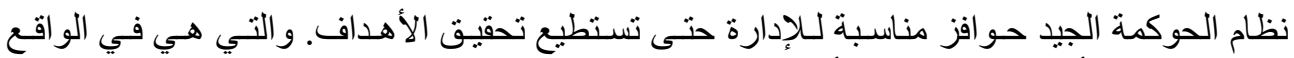

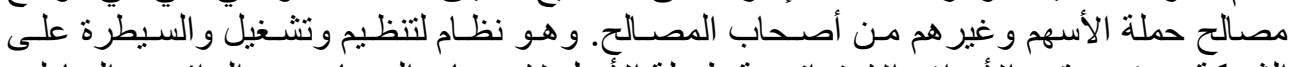

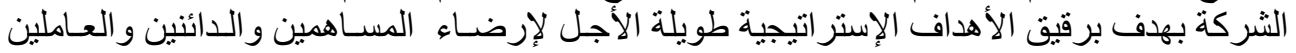

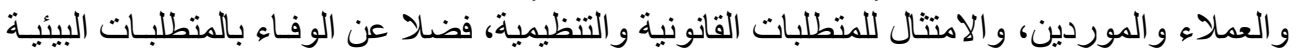

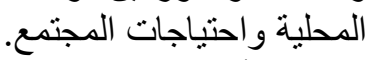

ويُعرف الكاتب Gabrielle O' Donovan" "حوكمة الشركات، بأنهـا السياسـات الداخليـة

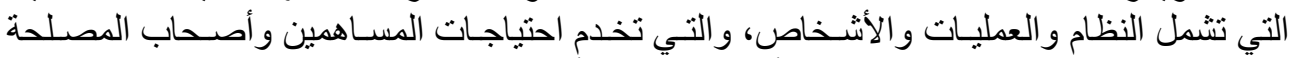

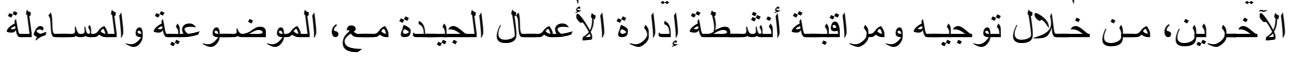

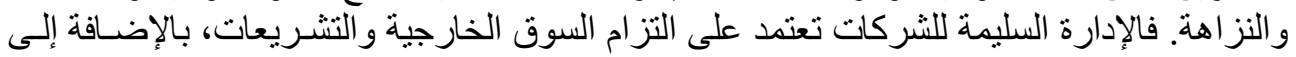

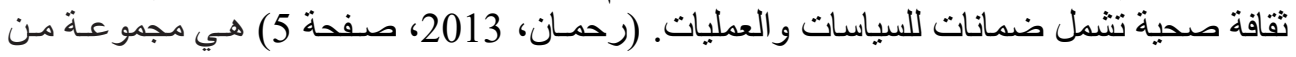

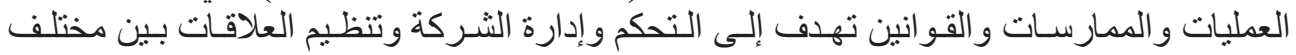

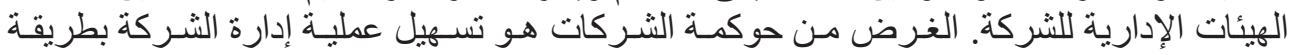

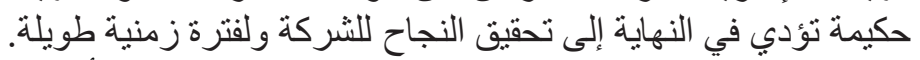

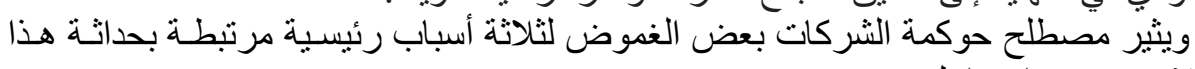

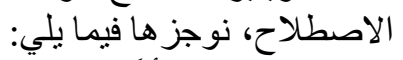

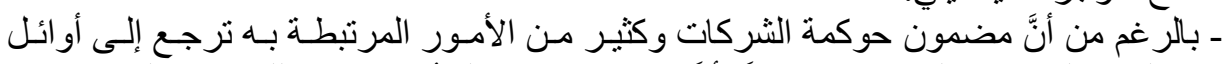

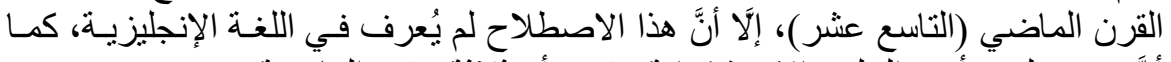

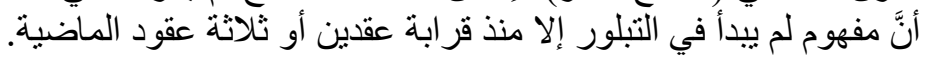

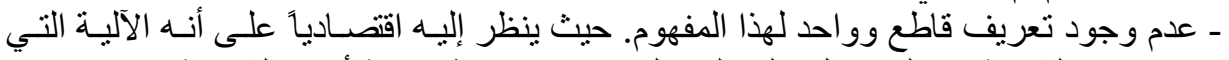

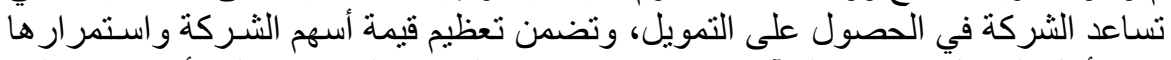

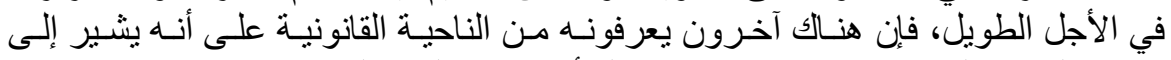

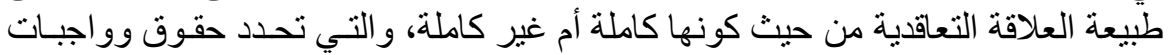

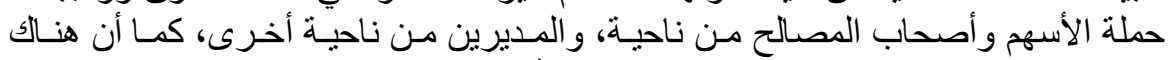

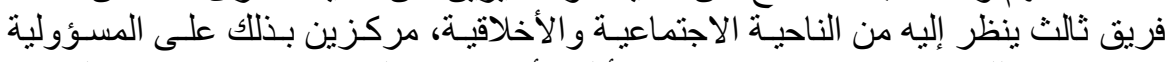

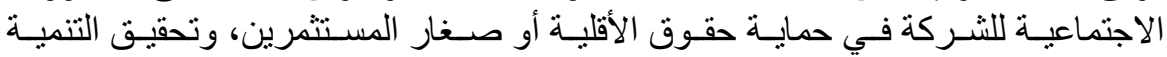
الاقتصادية العادلة، وحمائية البيئة.

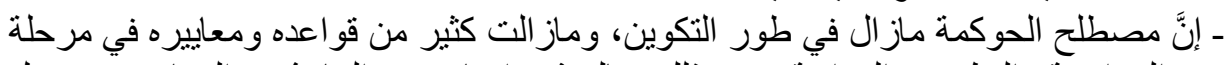

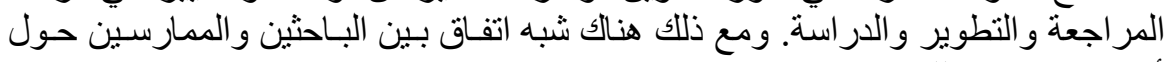

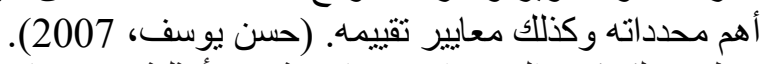

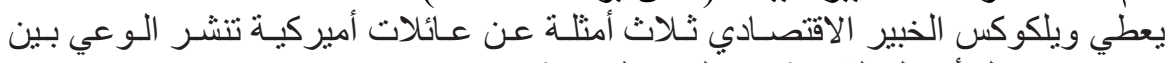

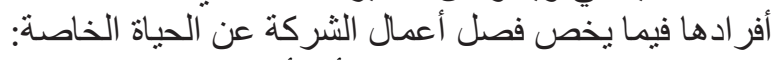

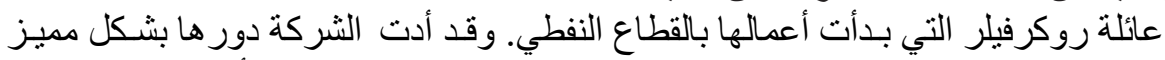

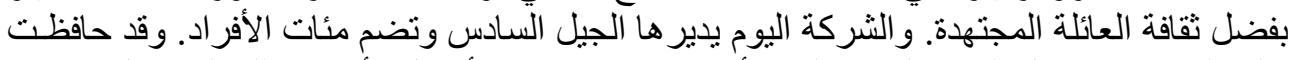

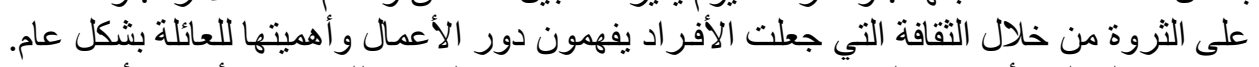

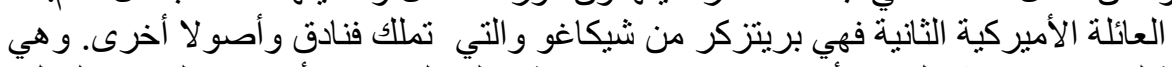

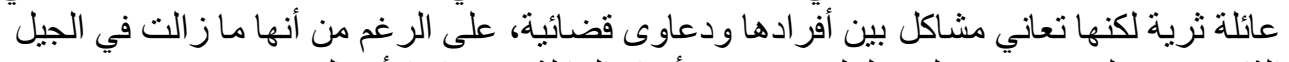

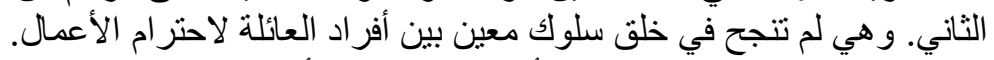

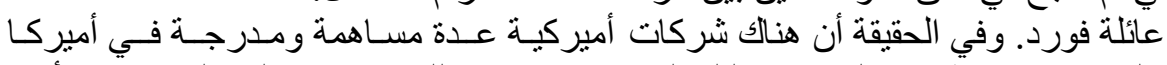

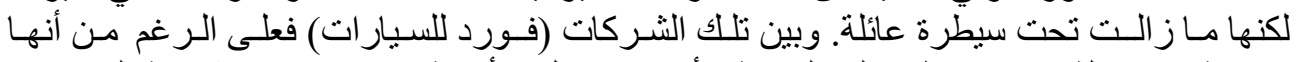

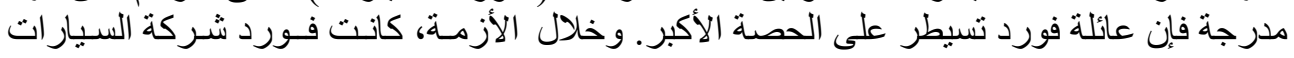




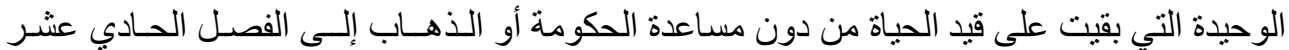

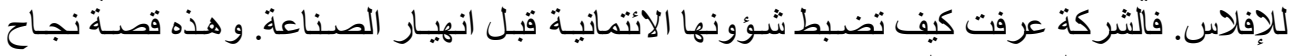
تستحق الاحتر ام لشركة عائلية مدرجة.

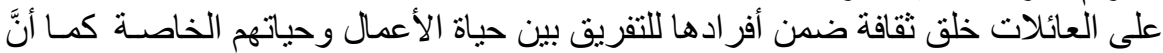

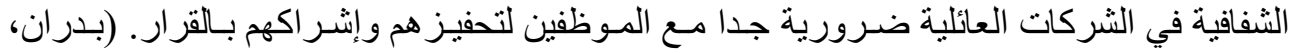

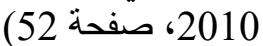

\section{3 مبادئ حوكمة الشركات}

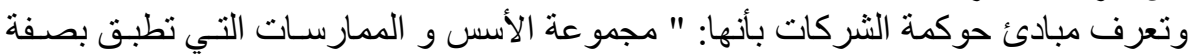

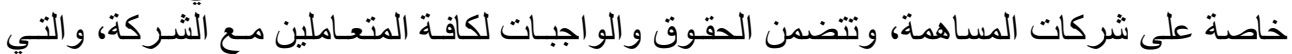

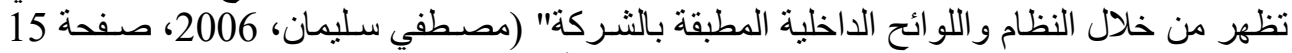

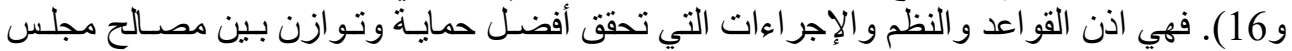

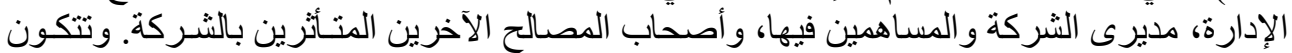

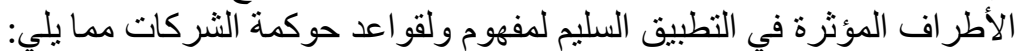

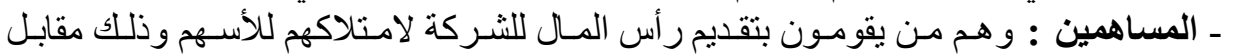

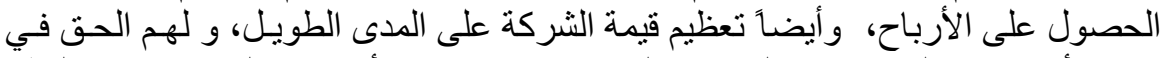

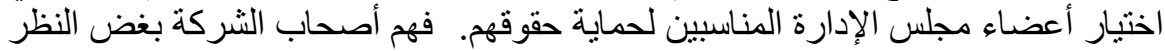

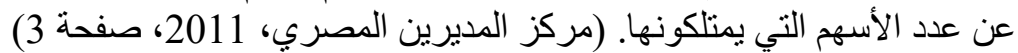

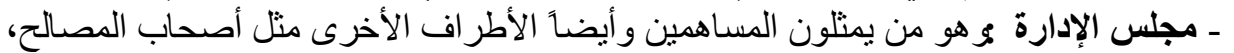

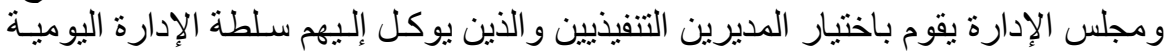

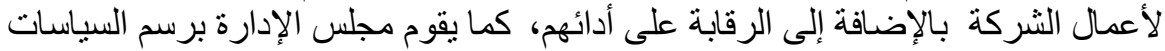

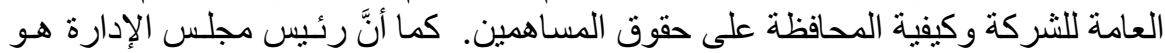

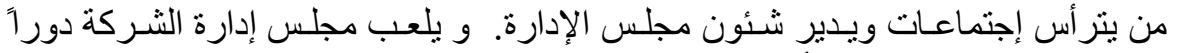

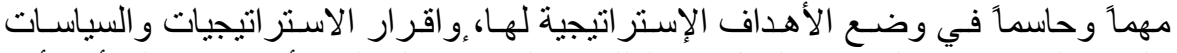

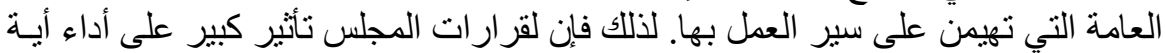

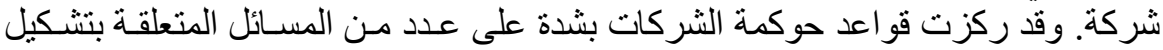

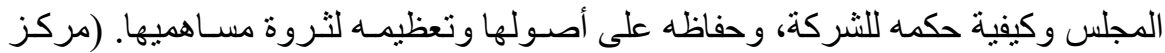

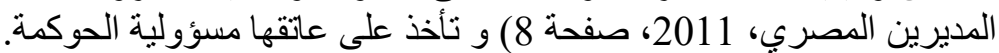
ـ الإدارة: و هي المسئولة عن الإدارة الفعلية للثركة وتقديم التقارير الخاصة بالأداء إلى مجلس

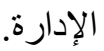

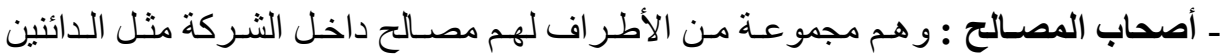

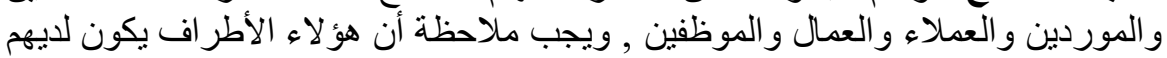

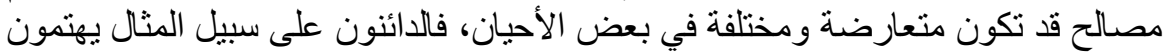

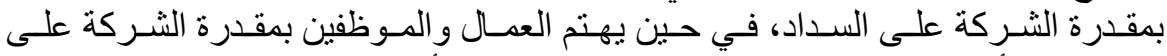

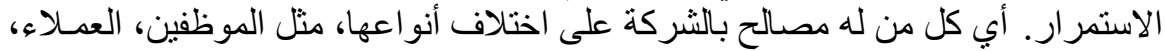
المور الإين، الموز عين، والدين الدائنين. وتجدر الإشارة إلى أن مفهوم حوكمة الثركات الثات ينأثر بالعلاقات فيما بين الأطر اف في نظسام

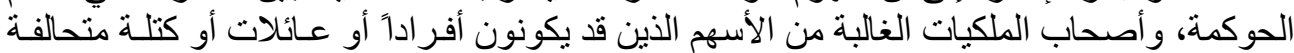
(مو لاي لخضر، واصحاب 2013، صفحة 191). 
المجلد 01 العدد 04 (2019) | ص 141-159

مجلـة بحوث الإدارة و الاقتصاد

حيث تسعى مبادئ الحوكمة لحماية حقوق حملة الأسهم و معاملة عادلـة لهم و وحمايـة دور

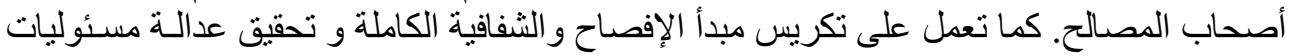
مجلس الإدارة.

ويتم تطبيق الحوكمة وفق خمسة مبادئ حسب منظمة التعاون الاقتصادي و التتمية (1999)

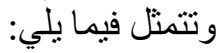

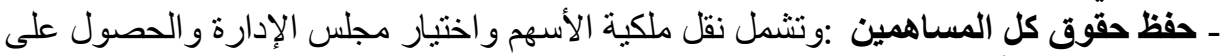

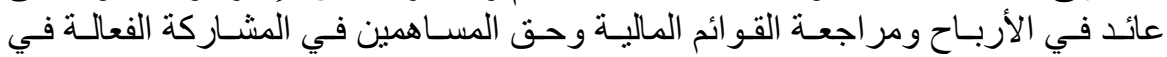
اجتماعات الجمعية العامة.

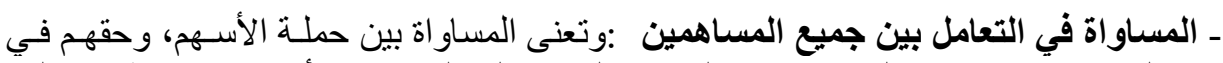

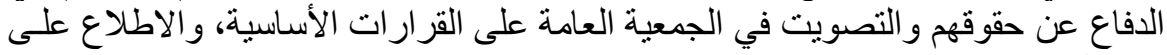
كافة المعاملات.

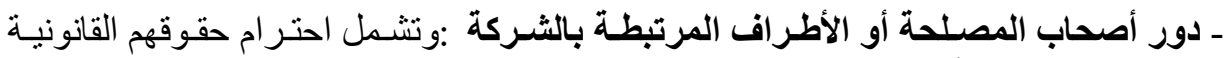

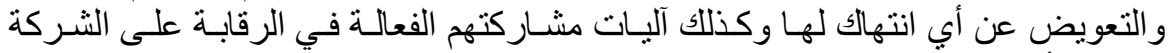

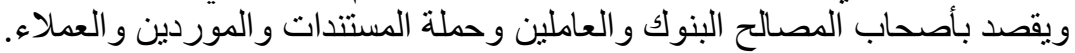

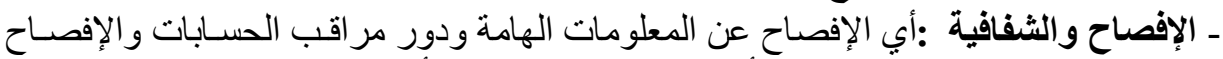

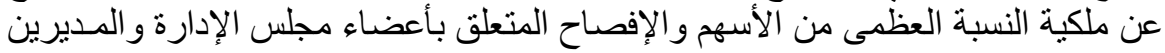

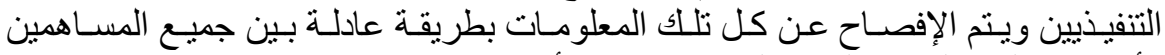

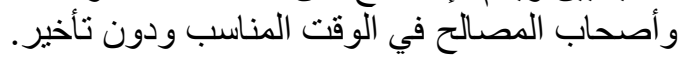

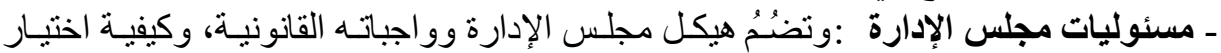

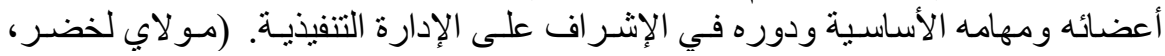

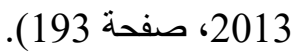

4.3 أهاف و إيجابيات تطبيق مبادئ الحوكمة في الثركات العائلية

1.4.3. أهداف الحوكمة في الثركات الثبات العائلية

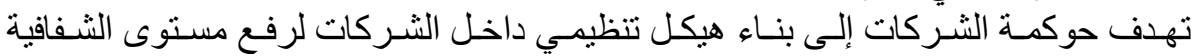

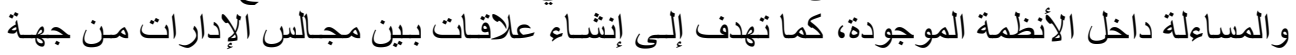

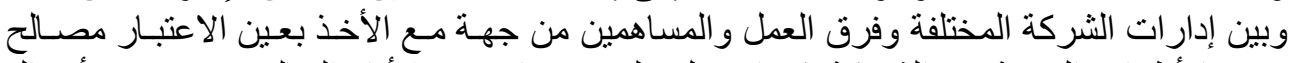

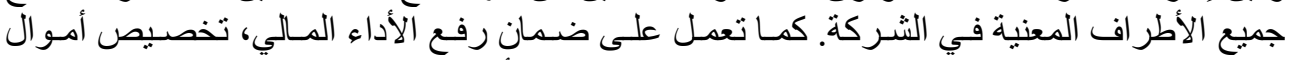

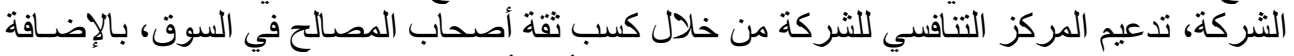

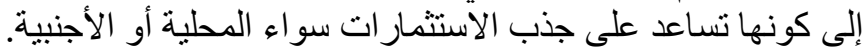
2.4 .3 نذكر بعض إيجابيات تطبيق مبادئ الحوكمة في الثركات الثرات العائلية التي نحصر ها في النقاط

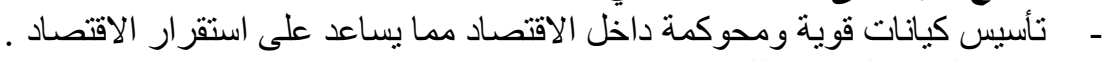

1.2.4.3 منافع تعود على الاقتصاد المحلي

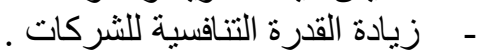

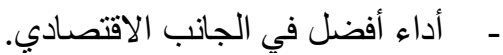

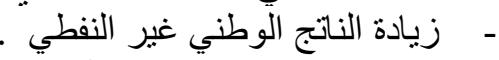

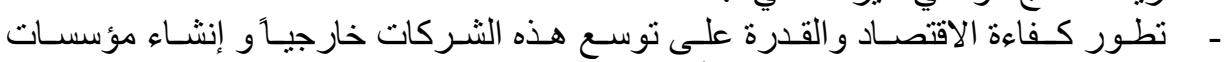

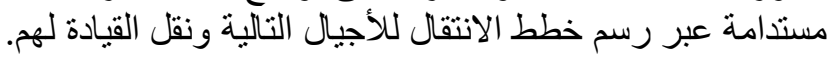


2.2.4.3 منافع تعود على أفراد العائلة

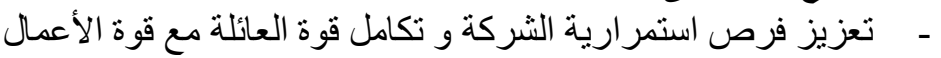

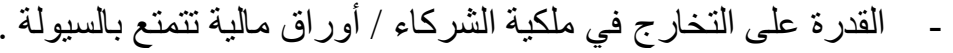

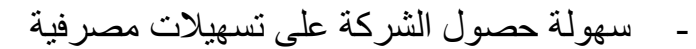

-

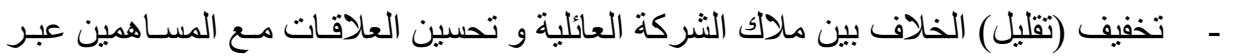

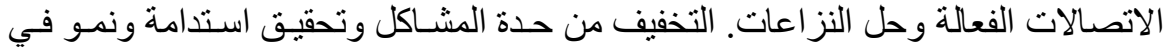

فترة قصيرة.

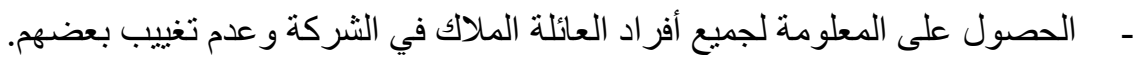

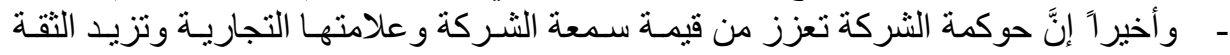
والقيمة المرتبطة بها.

\section{4. واقع حوكمة الشركات العائلية في الجزائر}

\section{4 تقليم الثركة، تظورها التاريخي و أهدافها}

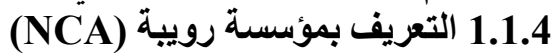

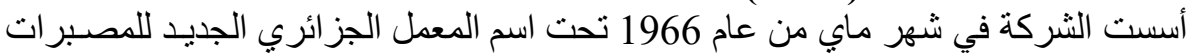

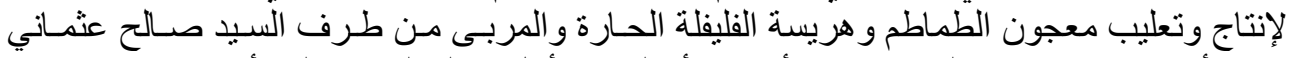

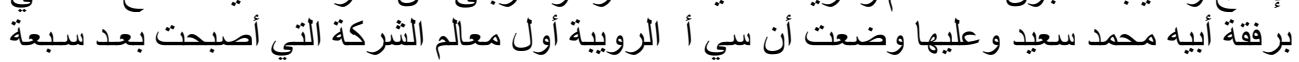

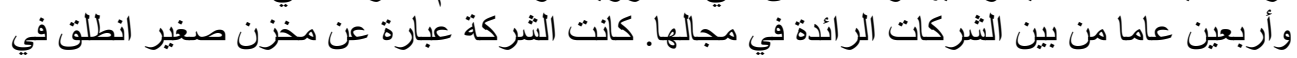

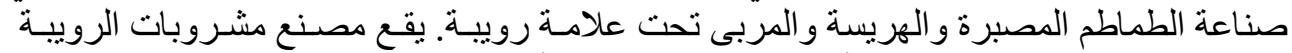

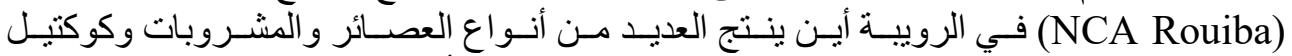

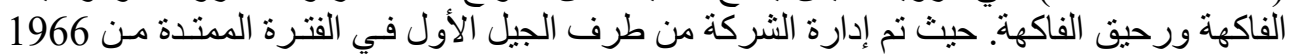

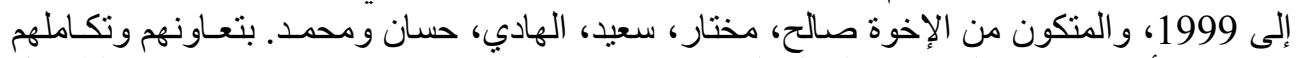

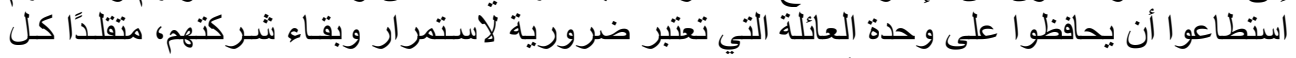

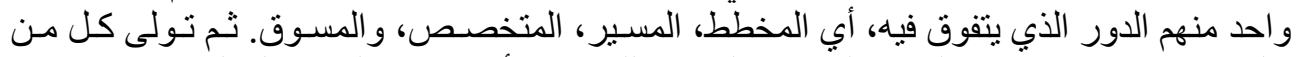

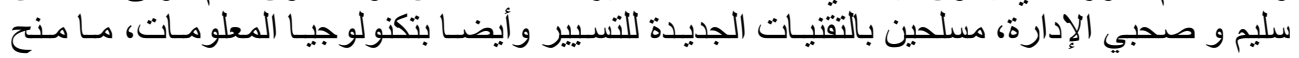

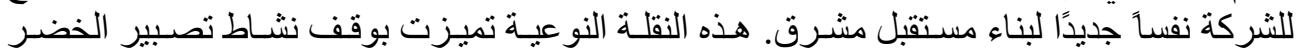

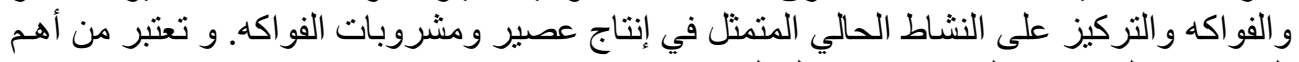
المؤسسات الر ائدة في الجز ائر في مجال العصائر النئ.

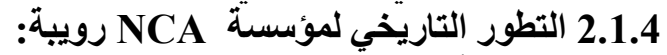
نلخص أهم تطورات التاريخية للشركة في الجدولة التطائي 


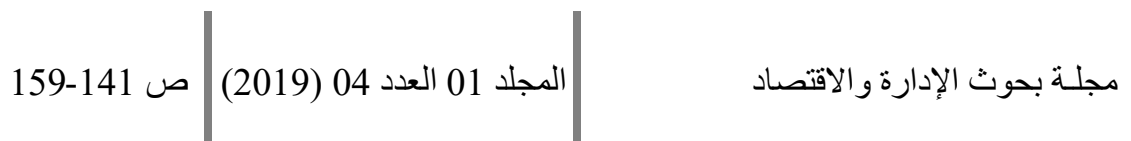

جدول رقم (3): التطور التناريخي لمؤسسة NCA رويبة

\begin{tabular}{|c|c|}
\hline التطورات التاريخية للثركة & 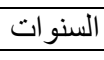 \\
\hline 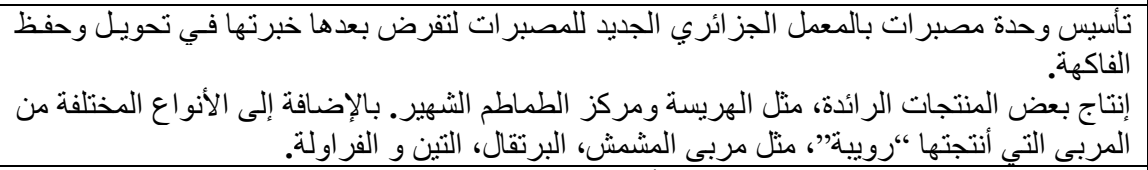 & 1966 \\
\hline 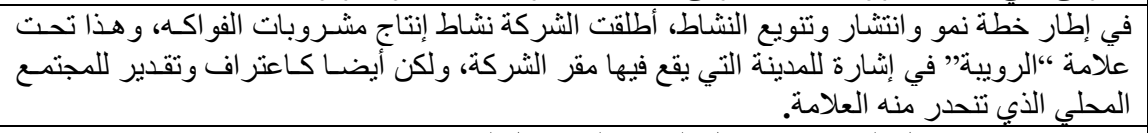 & 1984 \\
\hline 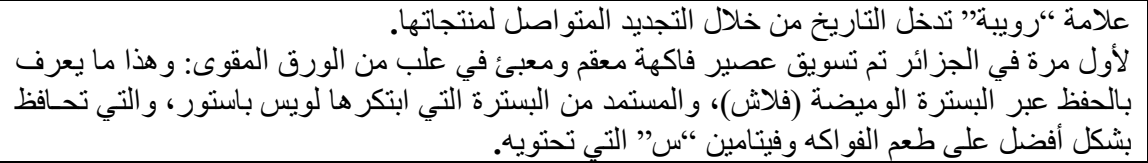 & 1989 \\
\hline الحصول علثي شهادة إيزو (المتئي عام بعد عام، فاستطاعت عرض تثكيلة كبيرة ومتنو عة من المنتجات. & 2000 \\
\hline 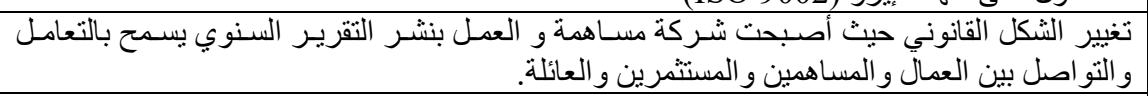 & 2003 \\
\hline توسيع النشاط السوق الدولية وفتح رأس المال لصندوق استثمار ات لمر افقة ودعم نمو الثركة. & 2005 \\
\hline الحصول على شهادة إيزو (ISO 14001) & 2007 \\
\hline الحصول على الجائزة الوطنية للبيئة و المحيط & 2008 \\
\hline تحديث شعار العلامة التجارية للمؤسئة مع تبني طرق جديدة في التعبئة و التغليف. & 2009 \\
\hline 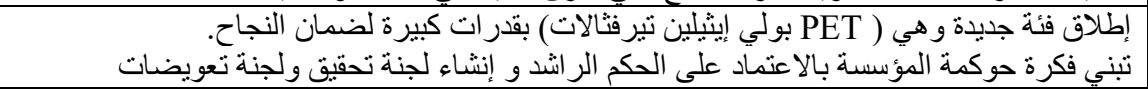 & 2010 \\
\hline 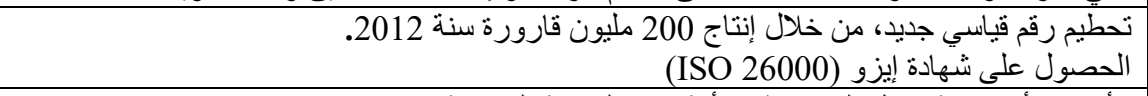 & 2012 \\
\hline 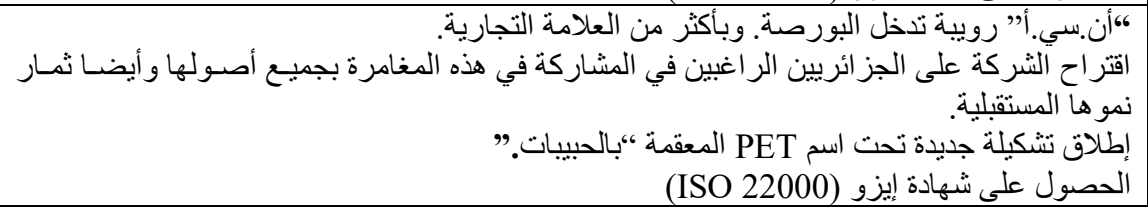 & 2013 \\
\hline 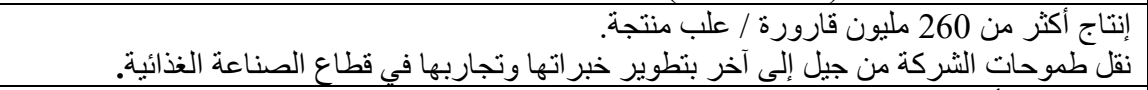 & 2014 \\
\hline 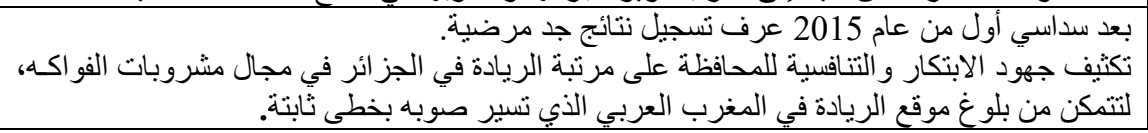 & 2015 \\
\hline
\end{tabular}

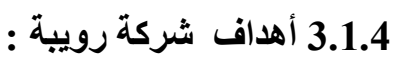

تطمح شركة رويية أن تصبح شركة معترف بها وطنيـا ودوليـا بحلـول عـام 2030، حيث تتطلع إلى:

ـ تطوير نموذج مرجعي لنطوير الثروة البشرية.

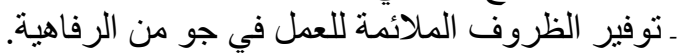

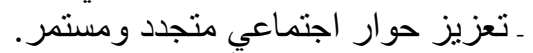

ـ تطوير و الحفاظ على أفضل نظل نظام للرواتب يكون محفز وقائم على أساس المهار ات و الأداء. 
و تعمل جاهدةً على تقديم منتوج صحي وترقية الاستهلاك المسؤول و المستدام، حيث تعتزم

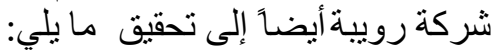
ـ منتجاتنا ستكون ذات نو عية صحية عالية: انعدام الحوادث المتعلقة بالأمن الغذائي النساجم عن

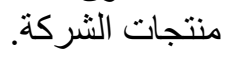

ـ 100\% من مستهلكي منتجات رويبة سوف يشاركون في حوار مبانشر مع الثركة.

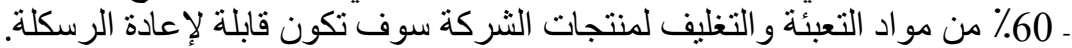

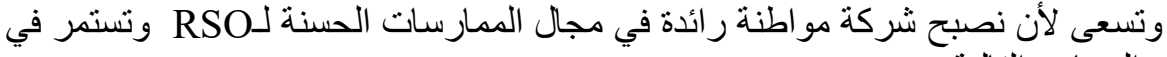

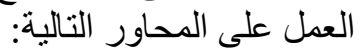

ـ تشجيع تطوير الممارسات الحسنة والأخلاق المهنية واحتر ام المعايير في عالم الأعمال.

ـ ـ المشاركة بطريقة فعالة في تحسين مناخ الأعمال في الجز ائر.

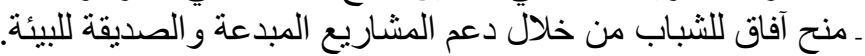

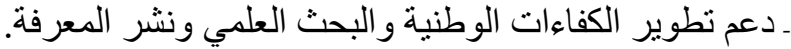

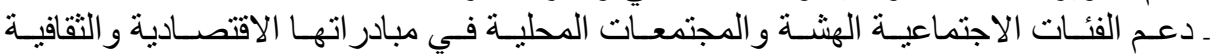

$$
\text { و والاجتماعية. }
$$

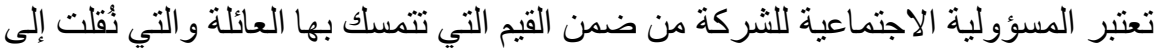

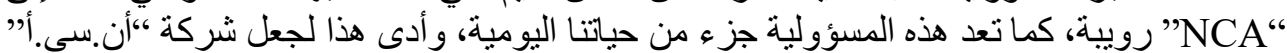
رويبة على رأس قائمة الثركات التي أدمجت المعيار “،إيزو "

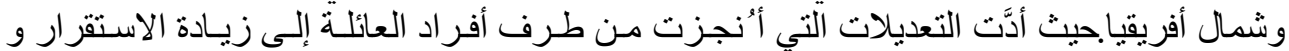
النمو فيها مما انعكس بالإيجاب على المؤسسة من حيث استمر اريتها و تطور ها. شكل رقم (1): مبادئ المسؤولية الاجتماعية لشركة رويية (NCA)

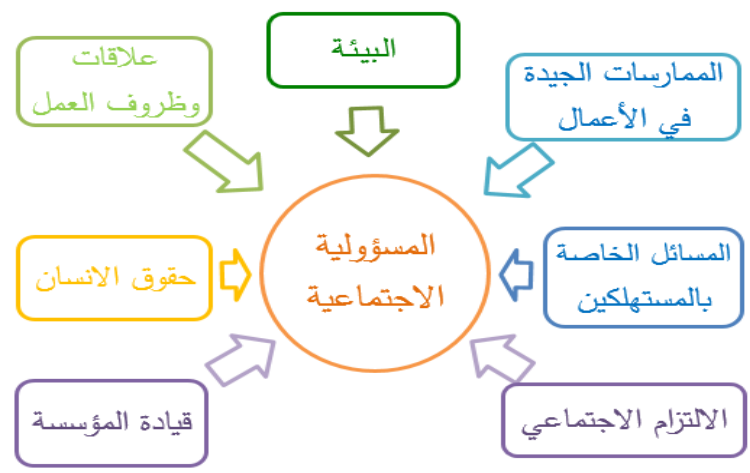

Source : www.rouiba.com.dz

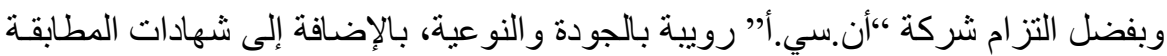

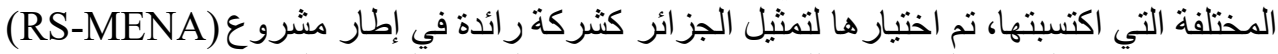

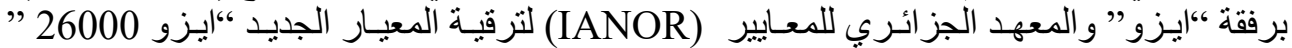

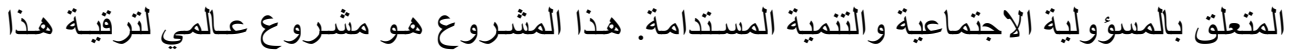

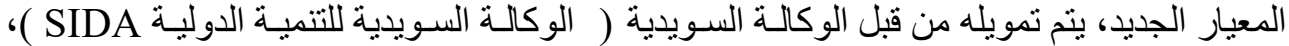

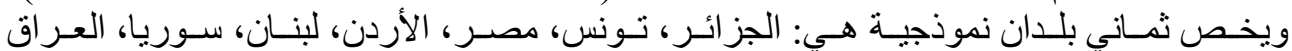

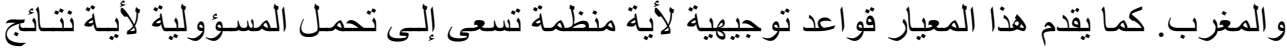
ناجمة عن قرار اتها و أنشطنها. 
المجلد 01 العدد 04 (2019) ص 141-159 ص

مجلـة بحوث الإدارة و الاقتصاد

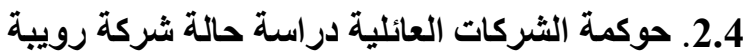

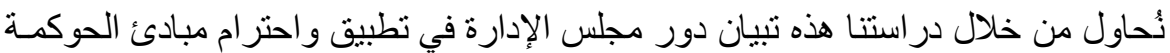

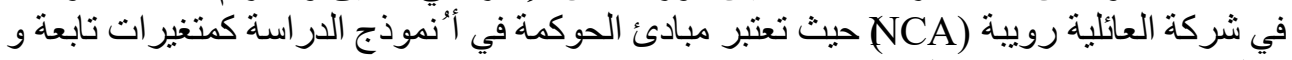

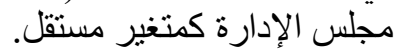
وقد احتوت الإستبانة على 25 سؤال (سؤالين حول خصائص العينة: الجنس و المستوى الدر اسي و وانس الباقي حول فقرات الأبعاد حو الي 23 سؤال )، حيث كانت نسبة الاسترداد 90 \% \% و وعدد الاستبيان

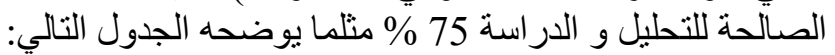

جدول رقم (4): الاستبيانات الصالحة للتحليل

\begin{tabular}{|c|c|c|c|c|}
\hline الصالحة للتحليليانات & عدد الاستبيانات الغير & الغير المستنردة الاستيانات & عدد الاستبيانات & 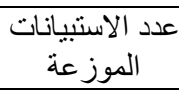 \\
\hline 60 & 12 & 8 & 72 & 80 \\
\hline$\% 75$ & $\% 15$ & $\% 10$ & $\% 90$ & $\% 100$ \\
\hline
\end{tabular}

المصدر: من إعداد الباحثة بالاعتماد على معلومات الاستبيان.

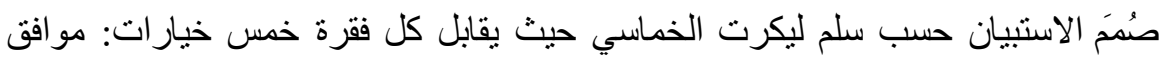

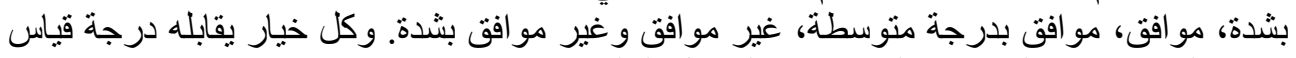

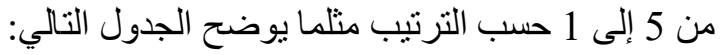
جدول رقم (5): سلم ليكرت

\begin{tabular}{|c|c|c|c|c|}
\hline لا أو افق بشدة & لا أو افق & أو افق قليلا & أو افق & مو افق بشدة \\
\hline 1 & 2 & 3 & 4 & 5 \\
\hline
\end{tabular}

المصدر : من إعداد الباحثة

1.2 .4 خصائص العينة: تتكون عينة الدر اسة من 60 فرد يمثل الذكور ما نسبته 87 \% و 68 \% 68 \%

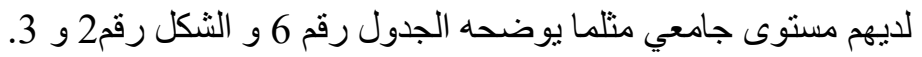
جدول رقم (6) : توزيع العبنة حسب الجنس

\begin{tabular}{|c|c|c|}
\hline النسب المئوية ( \% ) & التكر ارات & الجنس \\
\hline$\% 87$ & 52 & ذكور \\
\hline$\% 13$ & 8 & إناث \\
\hline$\% 100$ & 60 & لمجمو ع \\
\hline
\end{tabular}

المصدر : من إعداد الباحثة بالاعتماد على معلومات الاستبيان.

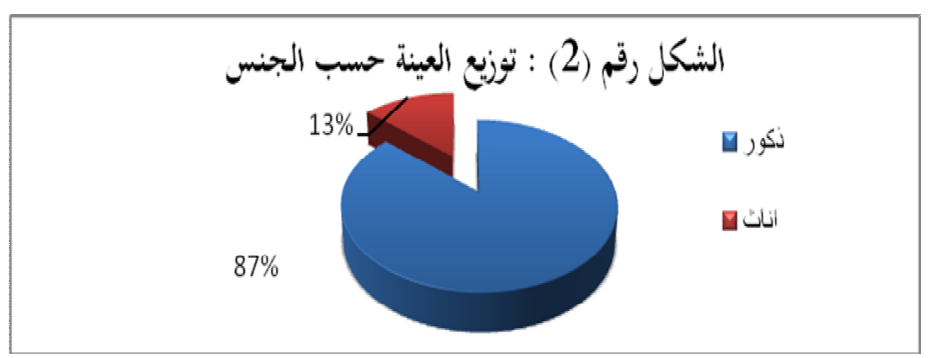

المصدر : من إعداد الباحثة 


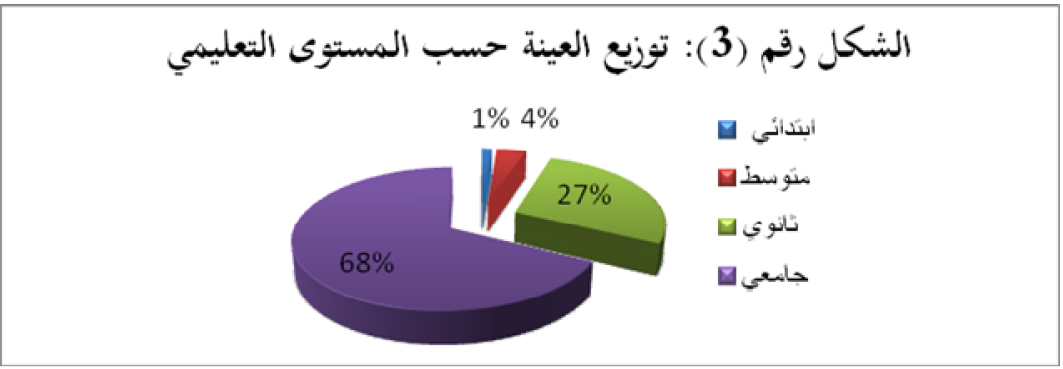

المصدر : من إعداد الباحثة بالاعتماد على معلومات الاستبيان.

2.2.4 التحليل الإحصائي لنتائج الدراسة و اختبار الفرضيات:

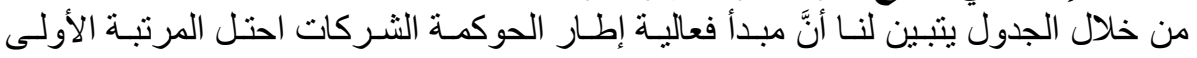

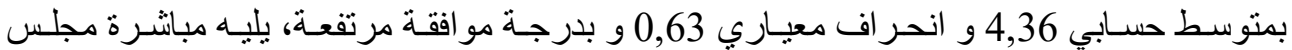

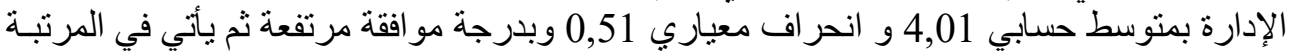

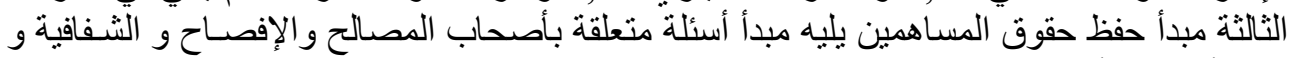
في الأخير مبدأ معاملة منساوية بين جمين الميع المساهمين.

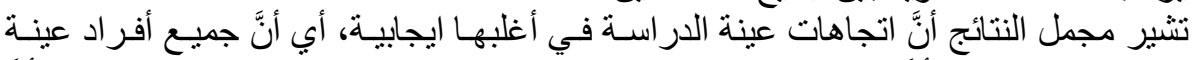

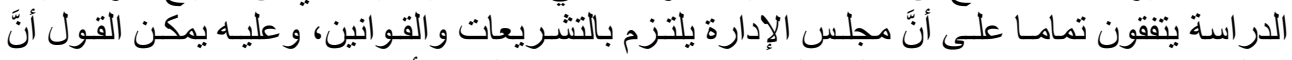

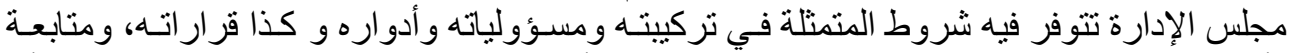

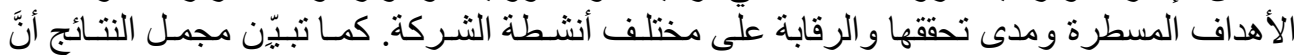

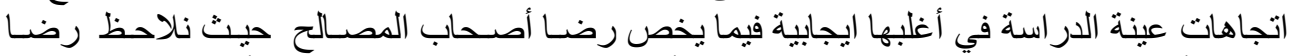

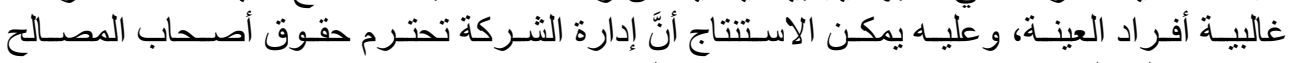

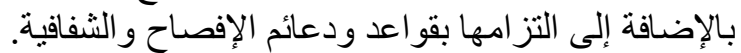

\begin{tabular}{|c|c|c|c|c|c|}
\hline الرتبة & 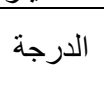 & المعياري & الحسابي & الفقرات & المتغيرات \\
\hline 3 & 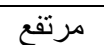 & 0,71 & 3,72 & 5 & حفظ حقوق المساهمين(1) \\
\hline 2 & مرتفع & 0,51 & 4,01 & 4 & مجلس الإدارة (2) مجل \\
\hline 1 & مرتفع & 0,63 & 4,36 & 4 & وجود إطار فعال لحوكمة الثركات(3) \\
\hline 6 & 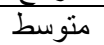 & 0,8 & 3,02 & 3 & معاملة متساوية بين جميع المساهمين (4) \\
\hline 4 & مرتفع & 0,49 & 3,62 & 3 & أسئلة متعلقة بأصحاب المصالح(5) \\
\hline 5 & 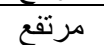 & 0,81 & 3,56 & 4 & الإفصاح و الثفافية (6) \\
\hline
\end{tabular}

المصدر : من إعداد الباحثة بالاعتماد على مخرجات SPSS V.23.

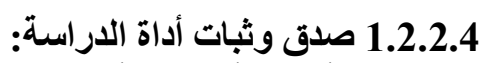

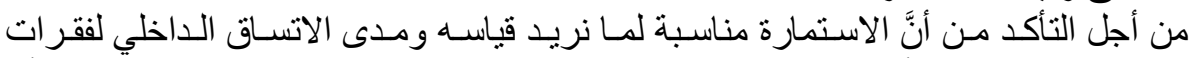

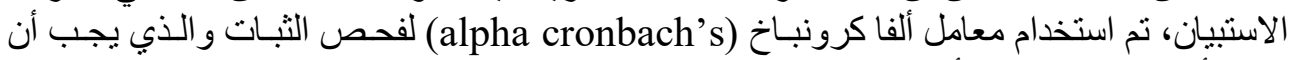

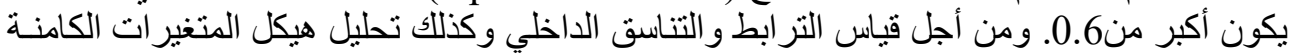

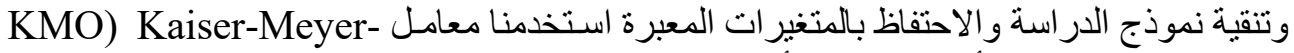

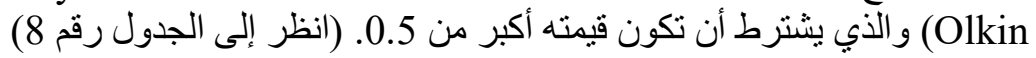




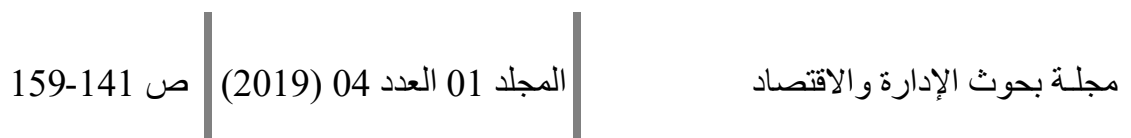

جدول رقم (8): ألفا كرونباخ، Rho de DG و KMO

\begin{tabular}{|c|c|c|c|c|c|}
\hline Sig & KMO & Rh de DG (ACP) & ألفا كرونباخ & عدد الفقرات & الأبعاد \\
\hline 0.00 & 0.812 & 0.841 & 0.734 & 5 & (1) \\
\hline 0.01 & 0.765 & 0.801 & 0.845 & 4 & (2) \\
\hline 0.02 & 0.693 & 0.854 & 0.742 & 4 & (3) \\
\hline 0.00 & 0.703 & 0.810 & 0.812 & 3 & (4) \\
\hline 0.00 & 0.831 & 0.823 & 0.658 & 3 & (5) \\
\hline 0.00 & 0.653 & 0.821 & 0.853 & 4 & (6) \\
\hline
\end{tabular}

* مناوين الأبعاد ذاتها في الجدول السابق.

المصدر : من إعداد الباحثة بالاعتماد على مخرجات SPSS V.23.

2.2.2.4

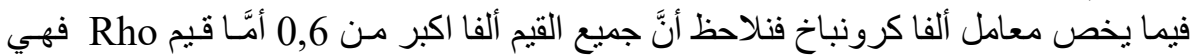

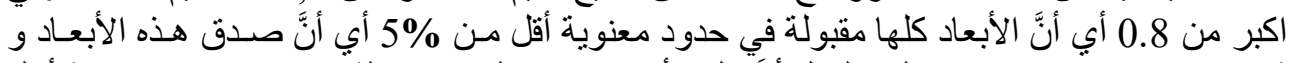

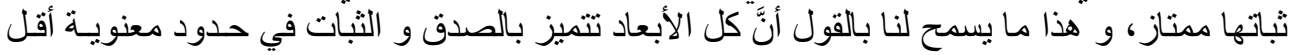

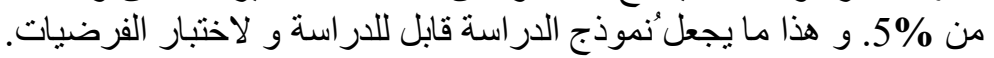

3.2.2.4 اختبار الفرضية:

لا يوجد اثر ذو دلالة إحصية فيائية لمبدأ مجلس الإدارة على مبادئ حوكمة الثركات العائلية عند

$$
\text { مستوى (0,05) في شركة رويبة (NCA). }
$$

جدول رقم (9): معاملات الارتباط لنموذج الانحدار

\begin{tabular}{|c|c|c|c|c|c|}
\hline Sign & Std. Error of the estimate & Adjusted R2 & $\begin{array}{c}\text { R-deux } \\
\text { (R2) }\end{array}$ & R & النموذج \\
\hline 0.000 & 0,141 & 0,628 & 0,636 & 0,798 & 1 \\
\hline
\end{tabular}

المصدر: من إعداد الباحثة بالاعتماد على مخرجات

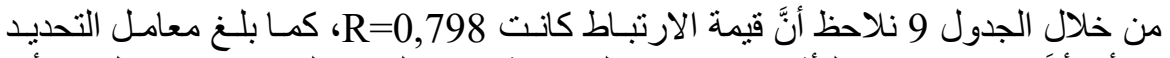

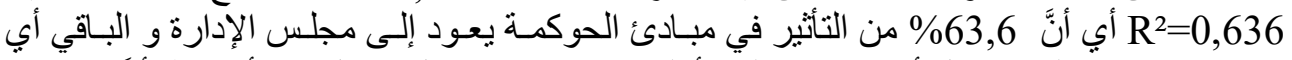

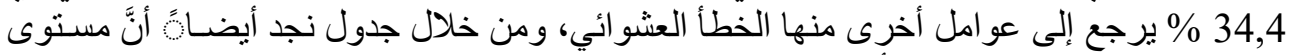

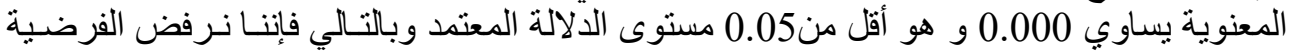

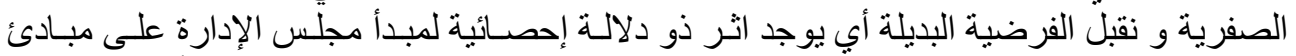

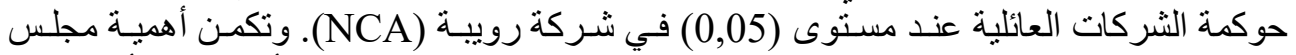

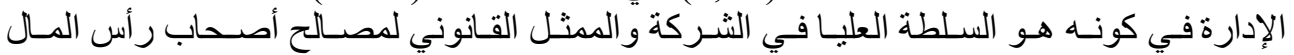

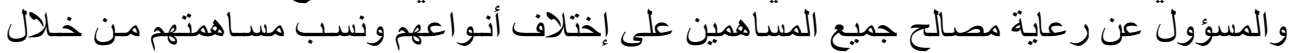

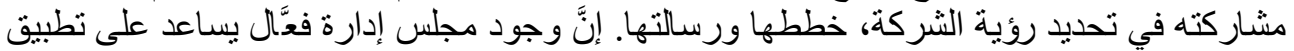

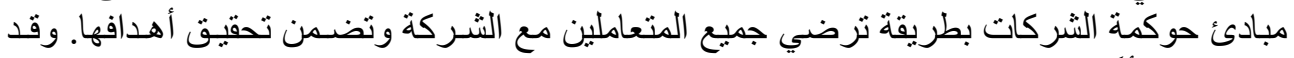

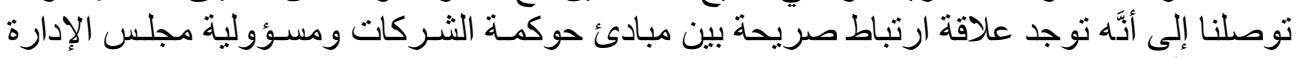

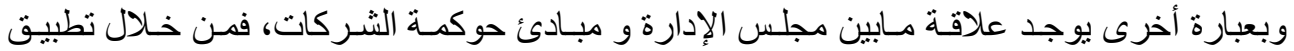

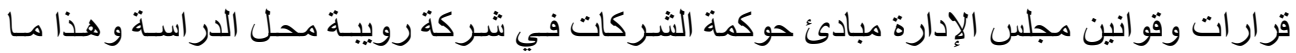
جعلها رائدة في السوق الجزائرية. 
دور مجلس الإدارة في تطبيق مبادئ حوكمة الثركات العائلية: شركة رويبة

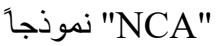

جدول رقم (10): معاملات الارنباط لنموذج الانحدار

\begin{tabular}{|c|c|c|c|c|c|}
\hline \multirow{2}{*}{ Sign } & \multirow{2}{*}{$\mathrm{T}$} & Stand Coefficients & \multicolumn{2}{|c|}{ Unstand Coefficients } & \multirow{2}{*}{ المتغير ات } \\
\hline & & $\mathrm{B}$ & Str. error & $\mathrm{B}$ & \\
\hline 0,02 & 11,45 & - & 0,471 & 5,13 & الحد الثابت \\
\hline 0,01 & 4,21 & 0,75 & 0,123 & 0,501 & المتغير المستقل \\
\hline
\end{tabular}

المصدر : من إعداد الباحثة بالاعتماد على مخرجات

يلعـبـ مجلس الإدارة دور هـام في تحسين فعاليـة حوكمسة الثـركات بحيـث يمكن صـياغة المعادلة التالية كالآتي:

مبادئ الحوكمة=

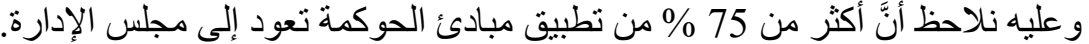

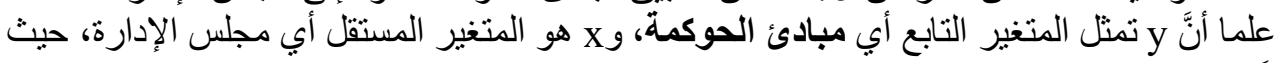

ـ الجزء الثابت هو يساوي 5,13؛

ـ معامل الانحدار هو $0,75$.

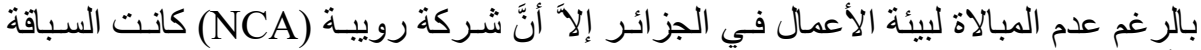

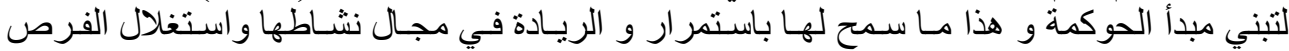

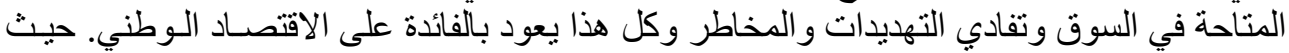

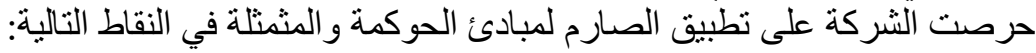

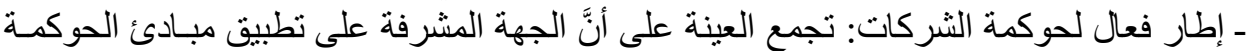

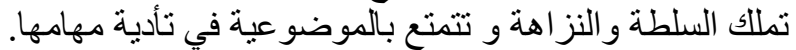

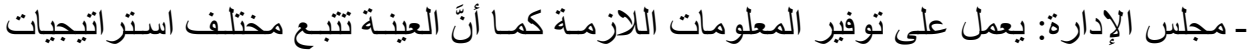

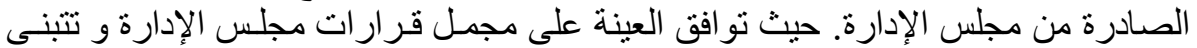
استر اتيجياته و تعليماته.

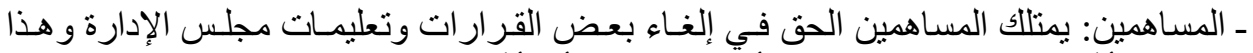

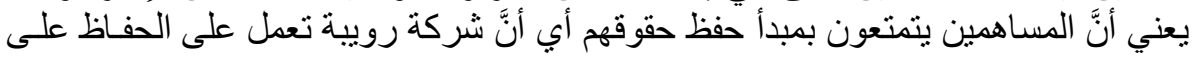
حقوق مساهمبها. ـ أصحاب المصالح: تتفق العينة على وجود آليات فعالة لحماية حقوق أصحاب المصالح في حالـة

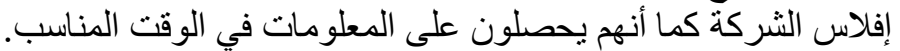

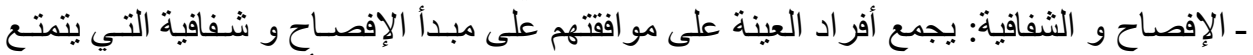

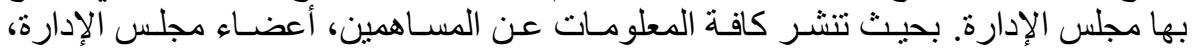

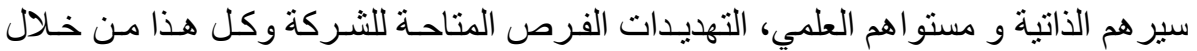

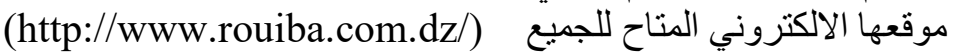

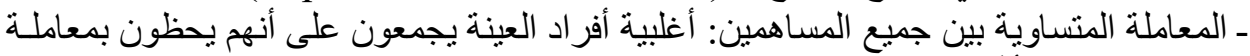

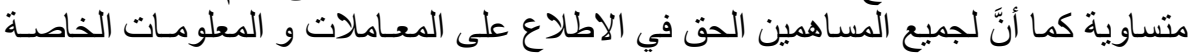
بشركة رويبة. كما أنَّ تبني الحوكمة من قبل شركة رويبة سمح لها بتحقيق الريادة والتربع على سوق

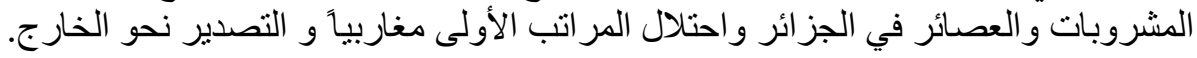




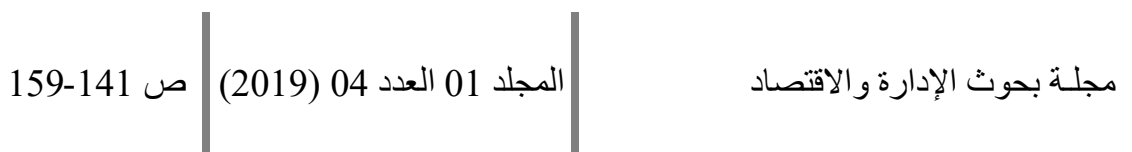

الخلاصة

ساهمت الإصـاحات التي تبنتها الجزائر في نمط تسير الثـركات إلى انتهـاج مفـاهيم جديـدة

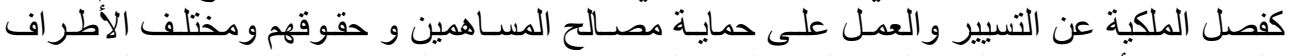

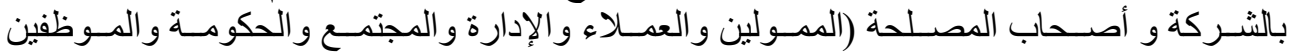

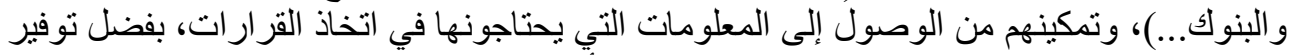

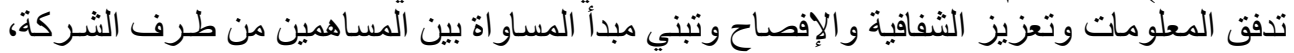

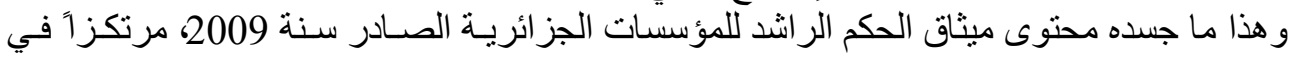

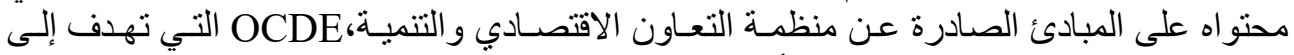
تسهيل عملية الحصول على التمويل وتأطير اليد العاملة، ويساهم في الحد من الممارسـات الاحتياليـة واستشر اف المخاطر و مختلف التهديدات.

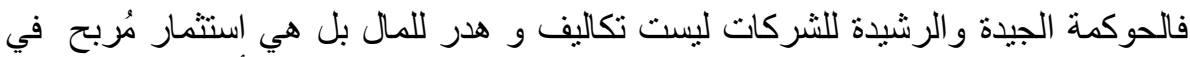

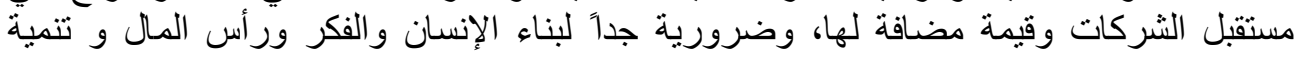

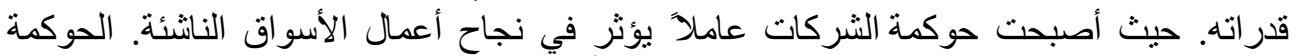

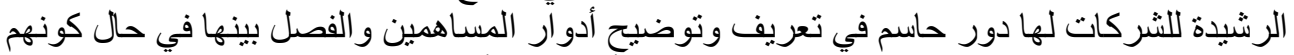

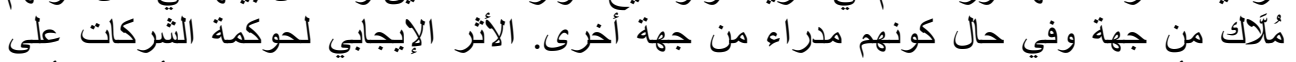

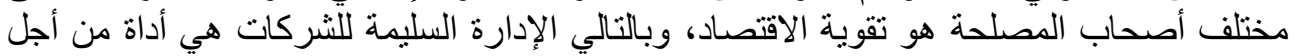

التنمية الاقتصادية والاجتماعية.

بناء على ما سبق نقتر ح التوصيات الأهن التالية:

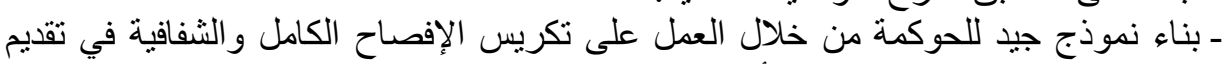

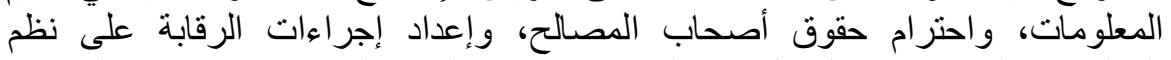
المعلومات المحاسبية، والفصل بين الوظائف بتحديد المسؤوليات، وما يترتب علبه عليها من

مساءلة.

ـ التركيز على تحقيق أهداف القوائم المالية كونها تساهم في القيام بالإشراف الفاء السليم وتوفير

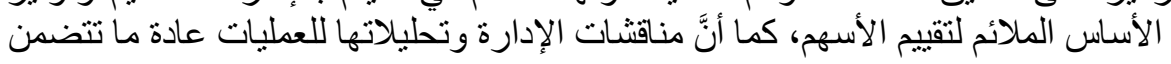

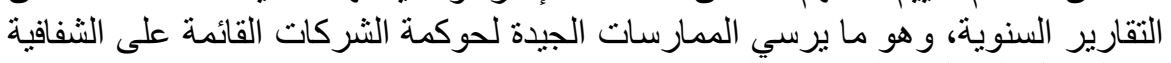
في التعامل الداخلي و الخار جي للتشركة. ـ تقديم المعلومات حول المخاطر المتوقعة والتهديدات المتعلقة بكافة نشاطات الشركة، يعد

عنصر مهم لممارسة الحوكمة الجيّدة. ـ الإلحاح في الاهتمام بموضوع الحوكمة ومدى تطبيقه في المؤسسات الصغيرة ولمدة والمتوسطة

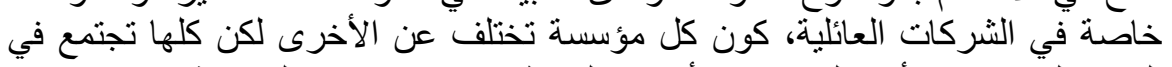

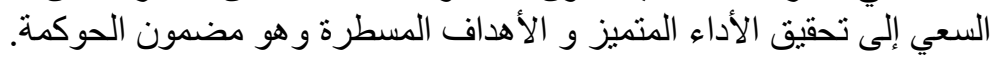

المراجع

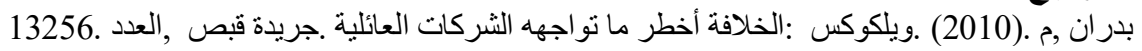

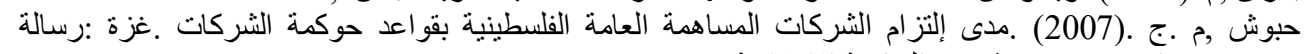
ماجستير غبر منشورة، الجامعة الإسلامية.

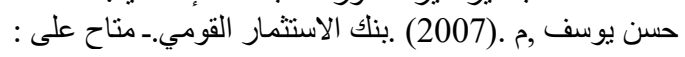
www.saaid.net/Doat/hasn/hawkama.doc (18-06-2017) رحمان , . . (2013) .نحو حوكمة جديدة للمؤسسات البترولية، الطاقات المتجددة في قلب التغيير .الملتقى العلمي الدولي التئي

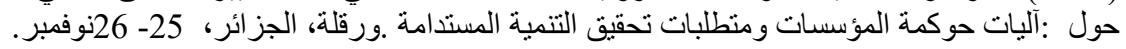

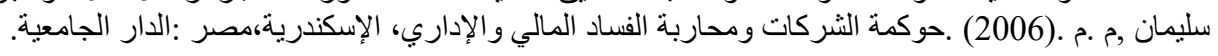




$$
\begin{aligned}
& \text { دور مجلس الإدارة في تطبيق مبادئ حوكمة الشركات العائلية: شركة رويبة } \\
& \text { "NCA" }
\end{aligned}
$$

صالح النجار رف .ج \& , .محمد علي ,ع . . . (2006) .الريـادة و إدارة الأعمـال الصـغيرة .عمـان، الأردن :دار حامـ

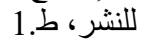

مركز الدر اسـات و البحـوث ـ ـ(2012) ـ در اسـة تفعيـل دور المـر أة في الثـركات العائليـة السـعودية .قطـاع الثـئون الاقتصادية :الغرفة الشرقية.

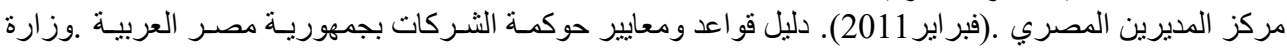

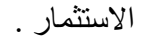

مناور ,ح . (2008). دور حوكمة الثركات في التنمية الإقتصادية، ورقة عمل في المؤتمر العلمي الأول حول حوكمـة

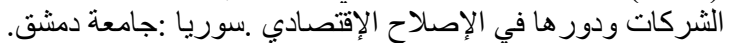

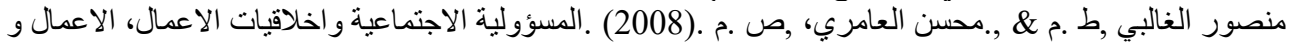

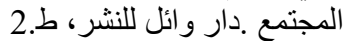

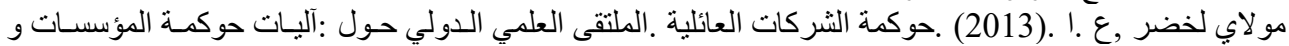

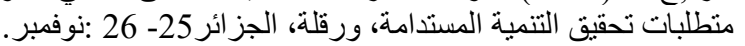

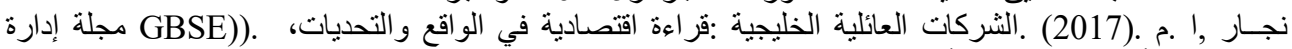

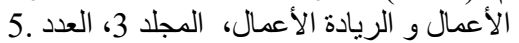

Mark L, U., Karen W., W., \& Daphyne S, T. (2004). Women As Family Business Successors. James Madison University, 19/5.

\section{References}

Badran, M. (2010). Wilcox: Succession is the most dangerous thing for family businesses.

QabasNewspaper, issue 13256. [In Arabic]

Habbouch, M.J. (2007). The extent of compliance of the Palestinian public shareholding companies with the rules of corporate governance. (Master Thesis, Islamic University, Gaza-Strip) [In Arabic]

Hassan, Y. M. (2007). The National Investment Bank, available at: www.saaid.net/Doat/hasn/hawkama.doc(18-06-2017) [In Arabic]

Rahman, A. (2013). Towards new corporate governance for oil companies, renewable energies are at the heart of change. International Scientific Forum on mechanisms for corporate governance and the requirements for achieving sustainable development. Ouargla, Algeria, 26-25 November. [In Arabic]

Suleiman, M. M. (2006). Corporate Governance and Fighting Financial and Administrative Corruption, Alexandria, Egypt: Al-dar Al-jamiya. [In Arabic]

Al-Najjar, S., F. J., \& Muhammad Ali, A. A. (2006). Entrepreneurship and small business management. Amman, Jordan: Hamed Publishing House, $1^{\text {st }}$ edition. [In Arabic]

Studies and Research Center. (2012). A study to activate the role of women in Saudi family companies. Economic Affairs Sector: Eastern Chamber. [In Arabic]

The Egyptian Directors Center. (February 2011). Guide to corporate governance rules and standards in the Arab Republic of Egypt. The Ministry of Investment. [In Arabic]

Munawer, H. (2008). The role of corporate governance in economic development, a working paper at the first scientific conference on corporate governance and its role in economic reform. Syria: University of Damascus. [In Arabic]

Al-Ghalbi, T. M., \& Al-Amri, S. M. (2008). Social responsibility and business ethics, business and society. Wael Publishing House, $2^{\text {nd }}$ ed. [In Arabic]

MoulayLakhdar, A. A. (2013). Family corporate governance. International Scientific Forum on Institutional Governance Mechanisms and Requirements for Achieving Sustainable Development, Ouargla, Algeria: 26-25 November. [In Arabic]

Najjar A. M. (2017). Gulf Family Businesses: Realistic Economic Reading and Challenges, GBSE)). Journal of Business Administration and Entrepreneurship, 3(5). [In Arabic] 
المجلد 01 العدد 04 (2019) || ص 141-159 |

مجلـة بحوث الإدارة و الاقتصاد

Role of the Board of Directors in Applying the Principles of Family Corporate Governance: Rouiba "NCA" as a Model

Fatima Sayeh ${ }^{1 \bullet}$

Received: 18-10-2019

Accepted: 23-12-2019

Published: 24-12-2019

\section{Abstract:}

Family corporate governance is receiving much attention, especially after the financial crises in the world. It balances and harmonises the interests of all parties related to the organisation and shareholders. In addition to tightening control over the management of companies to prevent them from abusing their authority and to provide transparency and reconfidence in accounting information using internal governance mechanisms, the most important of which is the Board of Directors. A field study at Rouiba shows that the Board of Directors has a statistically significant impact on corporate governance principles. It plays a vital role in improving the effectiveness of governance.

Keywords: Board of Directors, Governance, Family Corporate, Rouiba NCA.

JEL Classification: G3.

• Corresponding author: Relizane University Center (Algeria), [ $₫$ fatima.sayah@cu-relizane.dz] 